\title{
EXPERIMENTAL HYPERSONIC AERODYNAMIC CHARACTERISTICS OF THE SPACE SHUTTLE ORBITER FOR A RANGE OF DAMAGE SCENARIOS
}

\author{
G.J. Brauckmann and W. I. Scallion \\ NASA Langley Research Center, Aerothermodynamics Branch \\ Hampton, Virginia
}

\begin{abstract}
Aerodynamic tests in support of the Columbia accident investigation were conducted in two hypersonic wind tunnels at the NASA Langley Research Center, the 20-Inch Mach 6 Air Tunnel and the 20-Inch Mach $6 \mathrm{CF}_{4}$ Tunnel. The primary purpose of these tests was to measure the forces and moments generated by a variety of outer mold line alterations (damage scenarios) using 0.0075-scale models of the Space Shuttle Orbiter (approximately 10 inches in length). Simultaneously acquired global heat transfer mappings were obtained for a majority of the configurations tested. Test parameters include angles of attack from 38 to $42 \mathrm{deg}$, unit Reynolds numbers from 0.26 to $3.0 \times 10^{\wedge} 6$ per foot, and normal shock density ratios of 5 (Mach 6 air) and $12\left(\right.$ Mach $\left._{6} \mathrm{CF}_{4}\right)$.

The damage scenarios evaluated included asymmetric boundary layer transition, gouges in the windward surface acreage thermal protection system tiles, wing leading edge damage (partially and fully missing reinforced carboncarbon (RCC) panels), holes through the wing from the windward surface to the leeside, deformation of the wing windward surface, and main landing gear door and/or gear deployment. The aerodynamic data were compared to the magnitudes and directions observed in flight, and the heating images were evaluated in terms of the location of the generated disturbances and how these disturbance might relate to the response of discrete gages on the Columbia Orbiter vehicle during entry.

The measured aerodynamic increments were generally small in magnitude, as were the flight-derived values during most of the entry. Asymmetric boundary layer transition (ABLT) results were consistent with the flight-derived Shuttle ABLT model, but not with the observed flight trends for STS-107. The partially missing leading edge panel results best matched both the early aerodynamic and heating trends observed in flight. A progressive damage scenario is presented that qualitatively matches the flight observations for the full entry.
\end{abstract}

\section{INTRODUCTION}

The Space Shuttle Columbia suffered catastrophic failure during entry on February 1, 2003. The Orbiter was traveling approximately Mach 18 at an altitude of 201,000 feet when loss of signal occurred. An investigation into the cause of the accident was immediately initiated, culminating in the Columbia Accident Investigation Board's (CAIB) finding that the likely physical cause was a debris strike during ascent (foam insulation from the external tank) damaging the left wing leading edge which then allowed a breach of hot gas into the wing during entry ${ }^{1}$. The final report distills the results from a tremendous amount of time and effort expended by many teams and individuals, representing work in the various disciplines of aerodynamics, aerothermodynamics, structures, and more. This paper presents results from aerodynamic tests in support of the accident investigation conducted in two hypersonic wind tunnels at the NASA Langley Research Center. The primary purpose of these tests was to measure the forces and moments generated by a variety of outer mold line alterations (damage scenarios). Simultaneously acquired global heat transfer mappings were obtained for a majority of the configurations tested. Schlieren photography visualizing the shock structures in the flow was utilized when possible. The aerodynamic data are compared to the magnitudes and directions observed in flight, and the heating images are evaluated in terms of the location of the generated disturbances and how these disturbance might relate to the response of discrete gages on the Columbia Orbiter vehicle during entry.

The initial information available to investigators after the loss of STS-107 was video footage of the foam strike somewhere on the left wing of Columbia, off-nominal temperature and pressure measurements in the left main landing gear wheel well, off-nominal temperature measurements from side fuselage bond-line thermocouples, and off-nominal aerodynamic moments (primarily rolling and yawing moments). Initial tests in the 20-Inch Mach 6 Air Tunnel concentrated on acreage tile damage to the lower left wing, boundary layer transition effects, and possible

Approved for public release; distribution is unlimited. 
main landing gear and door deployment. Subsequent testing in the 20-Inch CF4 Tunnel included landing gear and door deployment as well, but focused on damage to the wing leading edge as more detailed analyses of the video and on-board instrumentation, as well as forensic analysis of the recovered debris, led in this direction. The wing leading edge damage consisted of partially and fully missing reinforced carbon-carbon (RCC) panels. Other damage scenarios tested were holes through the wing from the windward surface to the leeside in the vicinity of the carrier panels, and deformation of the wing windward surface.

The flight aerodynamic forces and moments were defined using an iterative approach ${ }^{2,3}$. The known state of the Orbiter (vehicle attitude, trajectory parameters, vehicle mass properties, control surface position, and on-board measured angular rates) was used as input to a look-up routine in the Orbiter data book to define the nominal aerodynamic coefficients. Next, on-board measured accelerations and angular rates were used with the equations of motion to define the flight aerodynamic coefficients. The differences between these two sets of data were the unmodeled or delta aerodynamic coefficients, attributed to whatever damage was sustained by the Orbiter. These results were then used as input in a trajectory simulation that included other sources of aerodynamic moments such as winds and atmospheric uncertainties. When a good match was obtained between the trajectory simulation and the known flight trajectory, the delta aerodynamic moments were considered "final".

Figures $1 \mathrm{a}-1 \mathrm{c}$ show the final delta moments used for comparison to the wind tunnel data. Prior to 500 seconds after entry interface $(\mathrm{El})$ there were negligible effects on the Orbiter aerodynamics. The biases seen in the figures for this time period are considered within the uncertainty of the extracted data or were observed in other flights. After this time there is an increasing nose-left yawing moment, an increasing left-wing-down rolling moment, and an increasing nose-down pitching moment. These gradual trends continue for yawing and pitching moments until about 840 seconds after entry, then increase sharply. The rolling moment trend reverses at about 615 seconds, becoming positive (left-wing-up) at 760 seconds, and increasing sharply near loss-of-signal (LOS). Forces (normal, axial, and side) were not used as discriminators due to low resolution and other factors.

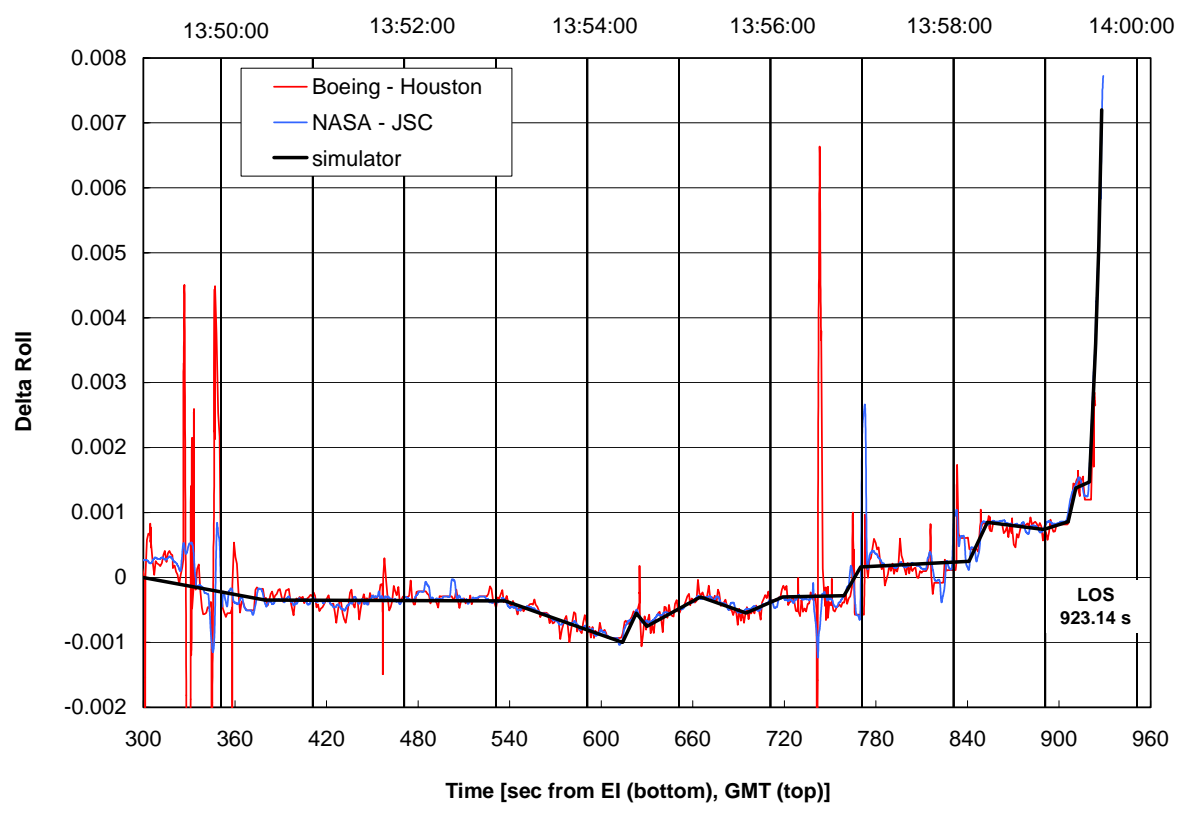

Figure 1a. Extracted flight delta rolling moment 


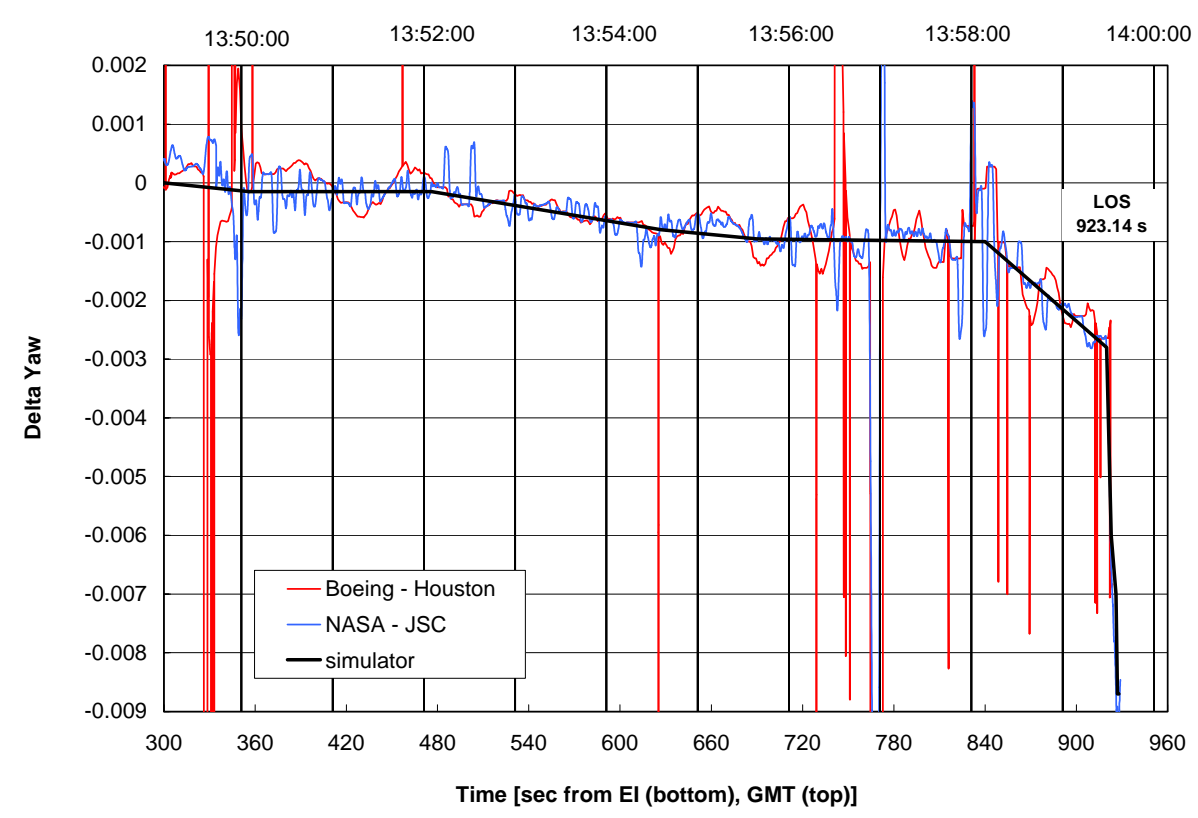

Figure 1b. Extracted flight delta yawing moment

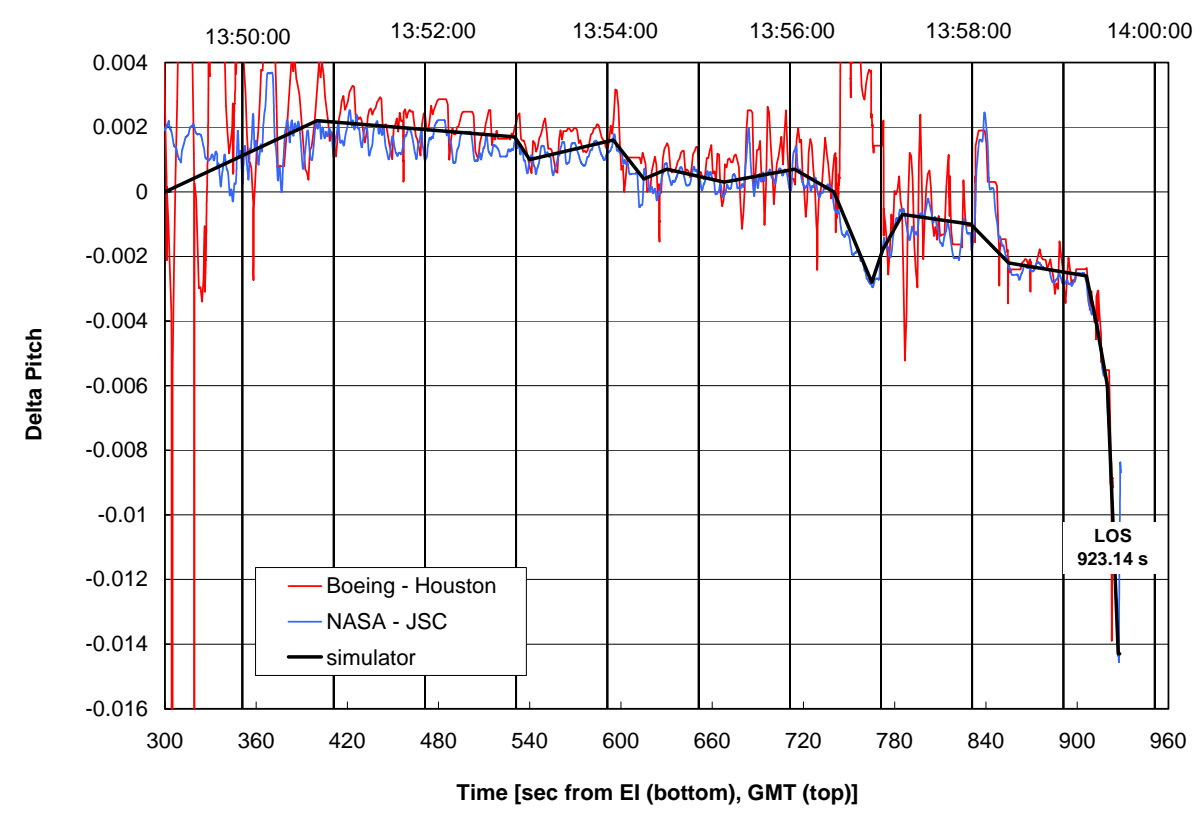

Figure 1c. Extracted flight delta pitching moment

FACILITIES, MODELS, AND TEST TECHNIQUES

WIND TUNNEL FACILITIES 
The two facilities used in this investigation were the 20-Inch Mach 6 Air Tunnel and the 20-Inch Mach $6 \mathrm{CF}_{4}$ Tunnel $^{4}$. These facilities are conventional (as compared to impulse), low-enthalpy, blow-down type hypersonic tunnels. The Mach 6 air tunnel uses heated, dried, and filtered air as the test gas. Typical operating conditions for the tunnel are: stagnation pressures from 30 to 500 psia; stagnation temperatures from 760 to $1000^{\circ} \mathrm{R}$, free stream Mach number from 5.8 to 6.1 ; free stream unit Reynolds numbers from 0.5 to 8 million per foot; a free stream and postnormal shock ratio of specific heats (gamma, $\gamma$ ) of 1.4; and a normal shock density ratio of 5.3. The facility has a twodimensional contoured nozzle leading to a closed, solid-wall test section with dimensions of 20.5 by 20 inches. The test core varies from 12 to 14 inches depending on the operating condition. Nominal run time is approximately 60 to 120 seconds, although longer runs times are possible.

The $\mathrm{CF}_{4}$ Tunnel uses heated, dried, and filtered carbon tetraflouride (Freon 14; molecular weight of 88 which is three times heavier than air) as the test gas. Typical operating conditions for the tunnel are: stagnation pressures from 85 to 2000 psia; stagnation temperatures up to $1300^{\circ} \mathrm{R}$, free stream Mach number from 5.9 to 6.0; free stream unit Reynolds numbers from 0.02 to 0.55 million per foot; a free stream gamma of 1.21 and a post-normal shock gamma of 1.10; and a normal shock density ratio of 11.7. The facility has a contoured axi-symmetric nozzle with a nozzle exit diameter of 20 inches, leading to an open-jet test section. The test core varies from 12 to 14 inches depending on the operating condition. Nominal run time is approximately 20 seconds.

The test conditions in the two facilities for the tests performed for this investigation are summarized in Table 1 below. The majority of the runs in the Mach 6 air tunnel were made at a length Reynolds number of 2.4 million (based on a reference body length of 1290.3 inches full scale), which corresponds roughly to flight at Mach 19 and 207,00 feet, near loss of signal. The majority of the runs in the $\mathrm{CF}_{4}$ tunnel were made at a length Reynolds number of 0.36 million, which corresponds roughly to flight at Mach 25 and 256,000 feet.

The loss of STS-107 occurred during entry at high Mach number and enthalpy levels, and relatively low Reynolds numbers. At these flight conditions high-temperature effects (i.e. flow chemistry) are significant due to the dissociation-recombination and ionization of the gas as it passes through the vehicle bow and wing shocks. These high-temperature effects increase the shock density ratio and lower the specific heat ratio (gamma) of the gas within the shock layer, causing shocks to lie closer to the vehicle surface and altering their interaction locations; these hightemperature effects cause the gas to expand to lower pressures than would occur for a non-reacting gas. The $\mathrm{CF}_{4}$ tunnel provides a simulation of these high-temperature effects via its low value of gamma, which is near the value in the Orbiter windward flow field at hypervelocity flight conditions. For example, lower pressure levels than expected on the rear windward portion of the Shuttle were identified as the root cause of the so-called Orbiter pitch-up anomaly that occurred during the first flight of Columbia, STS-1, wherein the Orbiter experienced a nose-up pitch increment relative to pre-flight predictions. The $\mathrm{CF}_{4}$ tunnel has been used to successfully demonstrate the magnitude and direction of this pitch-up increment ${ }^{5}$. While the ability of the $\mathrm{CF}_{4}$ tunnel to accurately simulate the leeside flow has not been validated to the extent of the windward flow, the damage scenarios investigated have their initiation on the wing leading edge and the windward surface, and thus the $\mathrm{CF}_{4}$ tunnel is expected to provide credible simulation of their effects. The Mach 6 air tunnel uses a perfect gas, but all the flow physics phenomena such as flow separationreattachment, boundary layer transition, and shock-shock interactions, will be present. The high-temperature effects may alter the level and location of these phenomena, but should not add or delete from them. Thus the Mach 6 air tunnel may be used as a preliminary or screening facility, with the $\mathrm{CF}_{4}$ tunnel used to refine the results. A more detailed discussion of the use of these facilities and their relation to the flight environment can be found in reference 6.

Table 1. Nominal Flow Conditions in NASA LaRC Aerothermodynamics Laboratory

$\begin{array}{lllcccc}\text { Facility } & \mathrm{M}_{\infty} & \mathrm{q}_{\infty}(\mathrm{psi}) & \mathrm{Pt}, 1(\mathrm{psi}) & \mathrm{Tt}, 1\left({ }^{\circ} \mathrm{R}\right) & \rho_{2} / \rho_{\infty} & \mathrm{Re}_{\infty} / \mathrm{ft}\left(\mathrm{x} 10^{6}\right) \\ \text { 20-Inch Mach 6 Air } & 5.90 & 1.04 & 60 & 890 & 5.2 & 1.0 \\ & 5.94 & 2.10 & 125 & 910 & 5.3 & 2.1 \\ & 5.96 & 3.05 & 180 & 910 & 5.3 & 3.0 \\ \text { 20-Inch Mach 6 CF } & 5.94 & 0.65 & 750 & 1180 & 11.7 & 0.27 \\ & 5.94 & 1.27 & 1330 & 1210 & 11.7 & 0.45\end{array}$

\section{WIND TUNNEL MODELS}

Two types of force-and-moment models were used in this investigation, one made from stainless steel and several from cast silica ceramic. The steel model was an existing 0.0075 -scale model that was modified to allow testing of gear and door deployment. A wheel well with a maximum depth of 0.35 inches was machined into the wing, a door was fabricated with a tab to allow installation on the model, and a simplified gear was constructed consisting of a single rod ending in a wheel assembly. The ceramic models were built from a mold that used the steel model as a pattern. Individual models were slip cast ${ }^{7,8}$, and then a steel sleeve was bonded to the inside to accept the straingage force balance. The ceramic models then had the locations of the RCC and carrier panels marked using a 
coordinate measurement system by the LaRC surface verification laboratory. Individual missing panels were removed using the location marks as a guide. Photographs of some of the various models and OML alterations are shown in figure 2. The gap between the inboard and outboard elevons was not modeled on the steel model. All models had $0^{\circ}$ control surface deflections of the elevons, body flap, and rudder. Although the control surfaces were deflected in flight, non-deflected control surfaces were used for simplicity as the data is presented in terms of changes, or deltas, from a nominal configuration.

\section{Wind Tunnel Model Configurations}

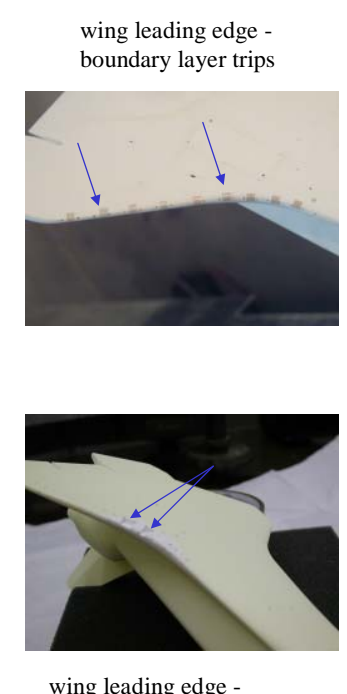

partial missing RCC panels main landing gear \& door
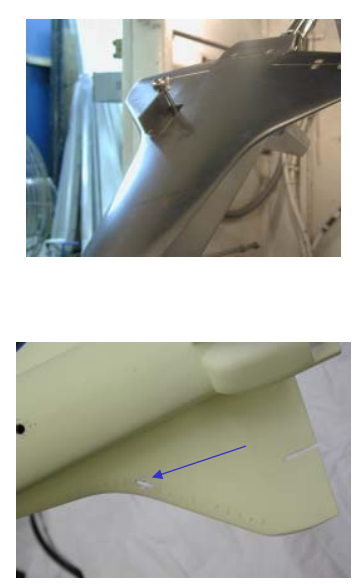

slot through wing carrier panel 8 wing leading edge full missing RCC panels
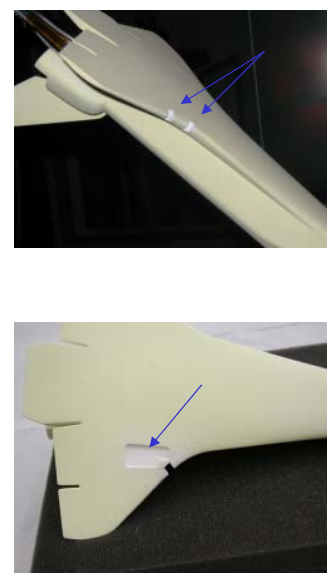

windward surface -

depression

(with missing RCC 9)

Figure 2. Wind tunnel model configurations

\section{TEST TECHNIQUES}

Force and moment measurements were obtained using a six-component water-cooled balance. The balance was selected to maximize accuracy of the lateral-directional data. One balance was used for the steel model and another for the lighter-weight ceramic models. Usual corrections for balance interactions, weight tares, and sting bending were made. A baseline (no damage, $0^{\circ}$ control surface deflections) set of aerodynamic coefficients was established for each model over an angle-of-attack range from $38^{\circ}$ to $42^{\circ}$. This baseline was then subtracted from subsequent runs of the different damage scenarios to provide the residual aerodynamic increments.

The global heat-transfer mappings in the Mach 6 air tunnel were obtained using an infrared (IR) imaging system ${ }^{9}$. The measured infrared radiation from the ceramic model was converted to surface temperatures. The global heattransfer mappings obtained in the $\mathrm{CF}_{4}$ tunnel were generated with the two-color relative-intensity phosphor thermography technique ${ }^{10,11}$ as IR techniques are not applicable to the $\mathrm{CF}_{4}$ tunnel where the freon gas absorbs infrared radiation. The ceramic models were coated with phosphors that fluoresce in two regions of the visible spectrum when illuminated with ultraviolet light. The fluorescence intensity is dependent upon the amount of incident ultraviolet light and the local surface temperature of the phosphors. A temperature calibration of the system conducted prior to the study is used to convert the ratio of green and red intensity images to temperature. For both the infrared and phosphor techniques, the global heat-transfer images are computed assuming one-dimensional semi-infinite heat conduction. The advantage of these techniques is their non-intrusive and global resolution of the quantitative heat-transfer data. These thermography techniques were used to identify the heating footprints associated with complex, three-dimensional flow phenomena such as boundary layer transition locations, flow separation and reattachment locations, etc. that would be extremely difficult to resolve using discrete measurement techniques. Figure 3 shows a ceramic model installed in the two facilities. The IR camera can be seen above the Mach 6 tunnel (photograph on left). A similar camera placement was used in the $\mathrm{CF}_{4}$ tunnel, as well as a side mounted camera for some runs. 

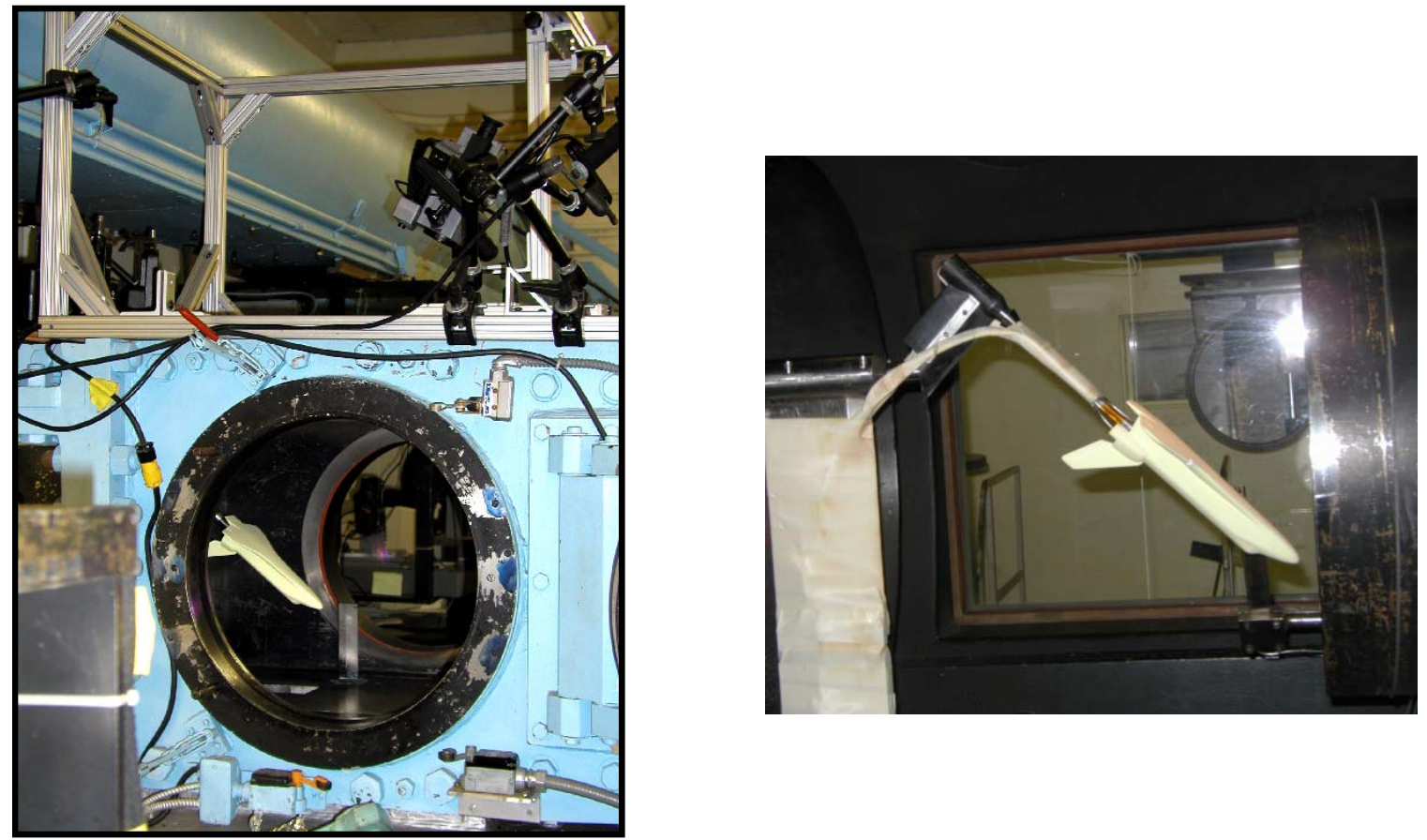

Figure 3. Photographs of model installed in the 20-Inch Mach 6 Air Tunnel (left) and 20-Inch $\mathrm{CF}_{4}$ Tunnel (right)

\section{DATA UNCERTAINTY}

The uncertainty of the wind tunnel data was estimated in three ways; as an average of the repeatability of the baseline runs for each model, as an average of the repeatability for 8 configurations with leading edge alterations, and as the uncertainty using the balance calibration (laboratory setting). The results are given in Table 2 and are expressed in terms of 2-sigma values of the coefficients. The steel model was tested using the same balance in both facilities. This same balance was used for the ceramic models in the 20-Inch Mach 6 Air Tunnel, while the ceramic models tested in the 20-Inch $\mathrm{CF}_{4}$ Tunnel used a smaller-load balance.

Table 2: Uncertainty estimates of the wind tunnel data

\begin{tabular}{|c|c|c|c|c|c|c|}
\hline Facility & Method & Models & $\mathrm{Re} / \mathrm{ft}$ & $\begin{array}{l}\text { Rolling } \\
\text { Moment }\end{array}$ & $\begin{array}{l}\text { Yawing } \\
\text { Moment }\end{array}$ & $\begin{array}{l}\text { Pitching } \\
\text { Moment }\end{array}$ \\
\hline 20-Inch Mach 6 Air & repeatability & baseline, steel & 3.0 & 0.00003 & 0.00006 & 0.00072 \\
\hline 20-Inch Mach 6 Air & repeatability & baseline, ceramic & 3.0 & 0.00007 & 0.00008 & 0.00044 \\
\hline 20-Inch Mach 6 Air & calibration & balance & 3.0 & 0.00006 & 0.00003 & 0.00048 \\
\hline 20-Inch Mach 6 CF4 & repeatability & baseline, steel & 0.46 & 0.00010 & 0.00007 & 0.0003 \\
\hline 20-Inch Mach 6 CF4 & repeatability & baseline, ceramic & 0.46 & 0.00009 & 0.00012 & 0.00042 \\
\hline 20-Inch Mach 6 CF4 & repeatability & altered, ceramic & 0.46 & 0.00023 & 0.00023 & 0.00024 \\
\hline 20-Inch Mach 6 CF4 & calibration & balance & 0.46 & 0.00009 & 0.00007 & 0.00015 \\
\hline
\end{tabular}




\section{RESULTS AND DISCUSSIONS}

\section{RESULTS FROM 20-INCH MACH 6 AIR TUNNEL}

\section{RAISED BOUNDARY LAYER TRIPS AND GOUGE}

At the beginning of the investigation the primary area of interest was damage to the acreage tiles on the windward surface of the left wing and the left main landing gear door, and possible early asymmetric boundary layer transition $(A B L T)$ caused by that damage. Boundary-layer transition was initiated in the wind tunnel by using small trips made of Kapton tape with a full-scale height of 0.6 inch. Damage scenarios tested in the Mach 6 air tunnel included a single boundary layer trip at RCC panel 6, a gouge in the center of the main landing gear door (full-scale dimensions approximately 7 by 32 by 4 inches), a raised main landing gear door (raised 1 inch full scale), and 7 trips arrayed span-wise across the leading edge of the door (to further simulate a raised door panel). In addition a "full" asymmetric transition configuration was tested which had 12 trips along the wing leading edge as well as 2 trips well forward near where surface protuberances were observed to cause early transition during flight of STS-28 ( $x / \mathrm{l}=0.26)$.

The extent of the turbulent flow generated by these disturbances is shown in figure 4 . The turbulent wedge from the single trip at RCC panel 6 is swept outboard and affects only the outermost portion of the left wing, as compared to the trips along the forward edge of the main landing gear door, which affect the flow more inboard. These individual trips were more effective than the raised door (image not shown) as the door acted more like a two-dimensional trip or step, which is not as effective in promoting turbulent flow. The gouge did not produce turbulent flow, although a small increase in heating was generated. The "full" asymmetric transition case is seen to provide turbulent flow over the aft $2 / 3$ of the left side of the model windward surface. The aerodynamic increments generated by these OML changes are shown in figures $5 \mathrm{a}$ (rolling moment) and figure $5 \mathrm{~b}$ (yawing moment). The gouge in the door and the raised door had minimal effect on the model aerodynamics. The single trip at RCC panel 6 and the 7 trips at the door leading edge had similar effects to each other, causing a positive rolling moment (right wing down) and a small negative yawing moment (nose left). All increments were less than the "full" ABLT condition.

All the transition-type damage scenarios examined generated rolling and yawing moments consistent in terms of direction with the flight-derived Shuttle ABLT model ${ }^{12}$, which is a positive rolling moment (right wing down) combined with a negative (nose left) yawing moment. These results are inconsistent with the extracted STS-107 flight data for the early portion of the flight, which have a left-wing down rolling moment combined with a nose-left yawing moment, indicating that asymmetric transition was not an initiating cause of the accident.

\section{Effect of raised trips and MLGD gouge \\ 20-inch Mach 6 Air $\alpha=40^{\circ} \quad \operatorname{Re}_{\mathrm{L}}=2.4 \times 10^{6}$}

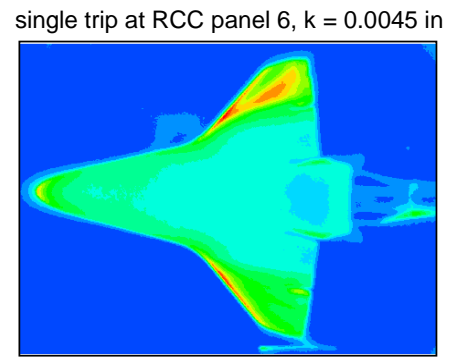

multiple trips $(\mathrm{k}=0.0045)$ - "full" asymmetric transition
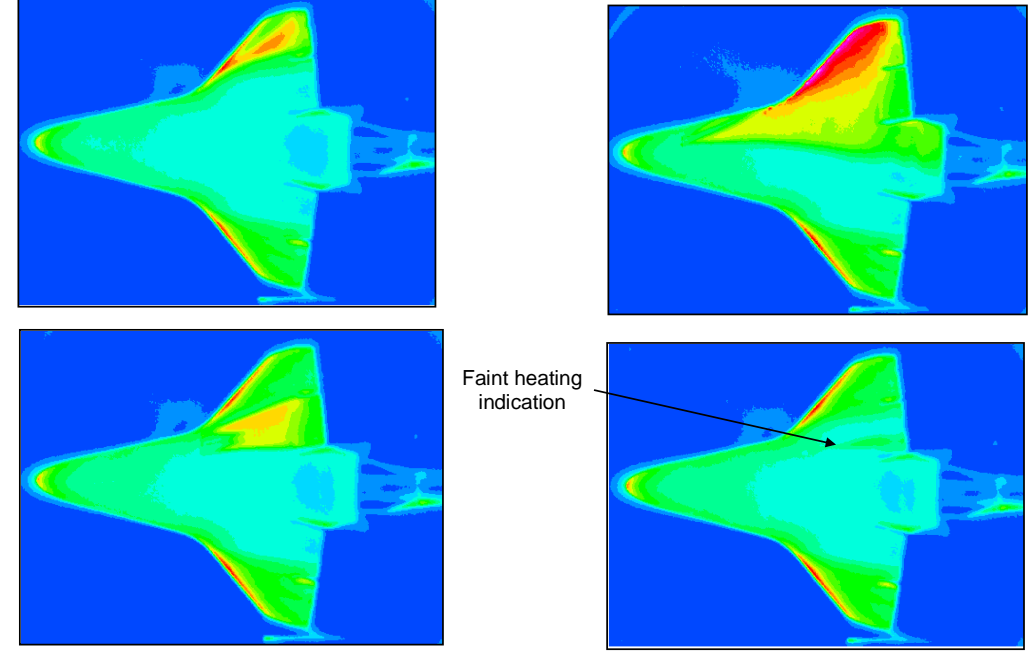

7 trips $(k=0.0045)$ along door leading edge

gouge in MLG door ( 0.028 deep)

Figure 4. Infra-red images of windward surface with various OML alterations 


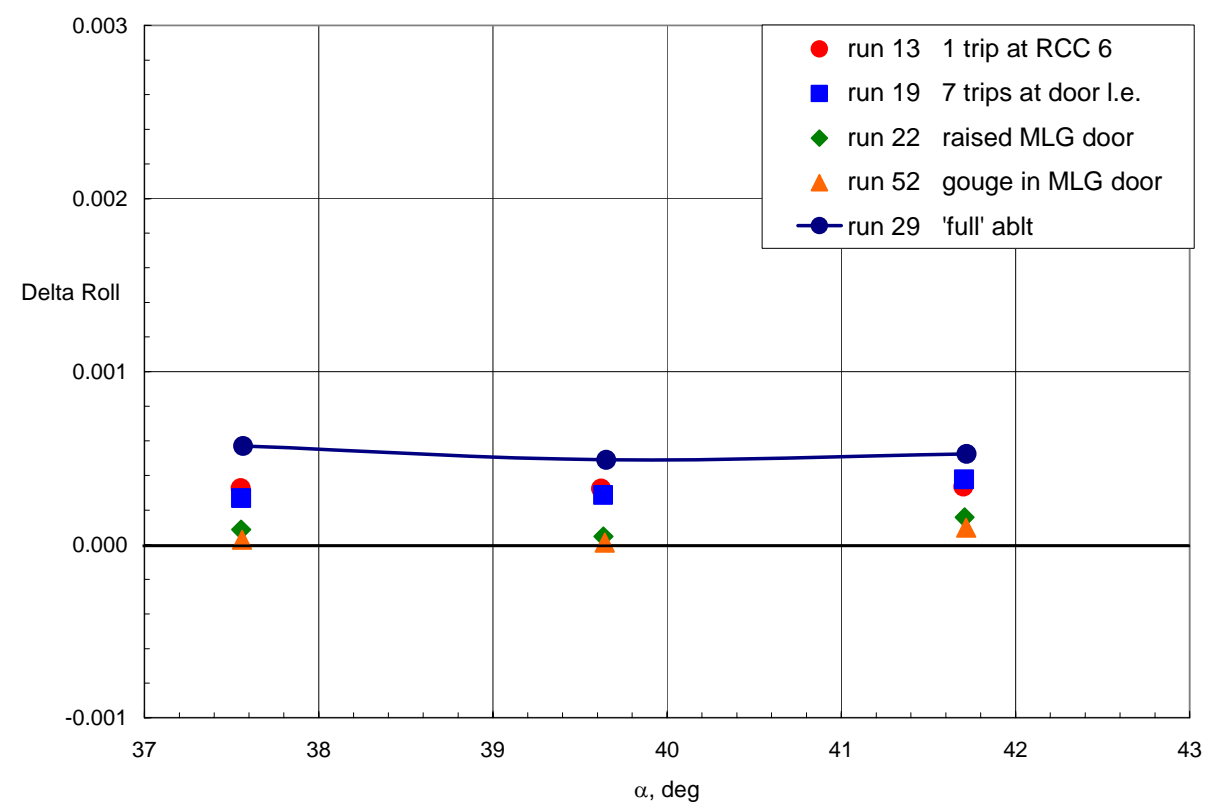

Figure 5a. Rolling-moment coefficient for various $O M L$ alterations $\left(M=6, \quad\right.$ Air, $\left.R e L=2.4 \times 10^{6}\right)$

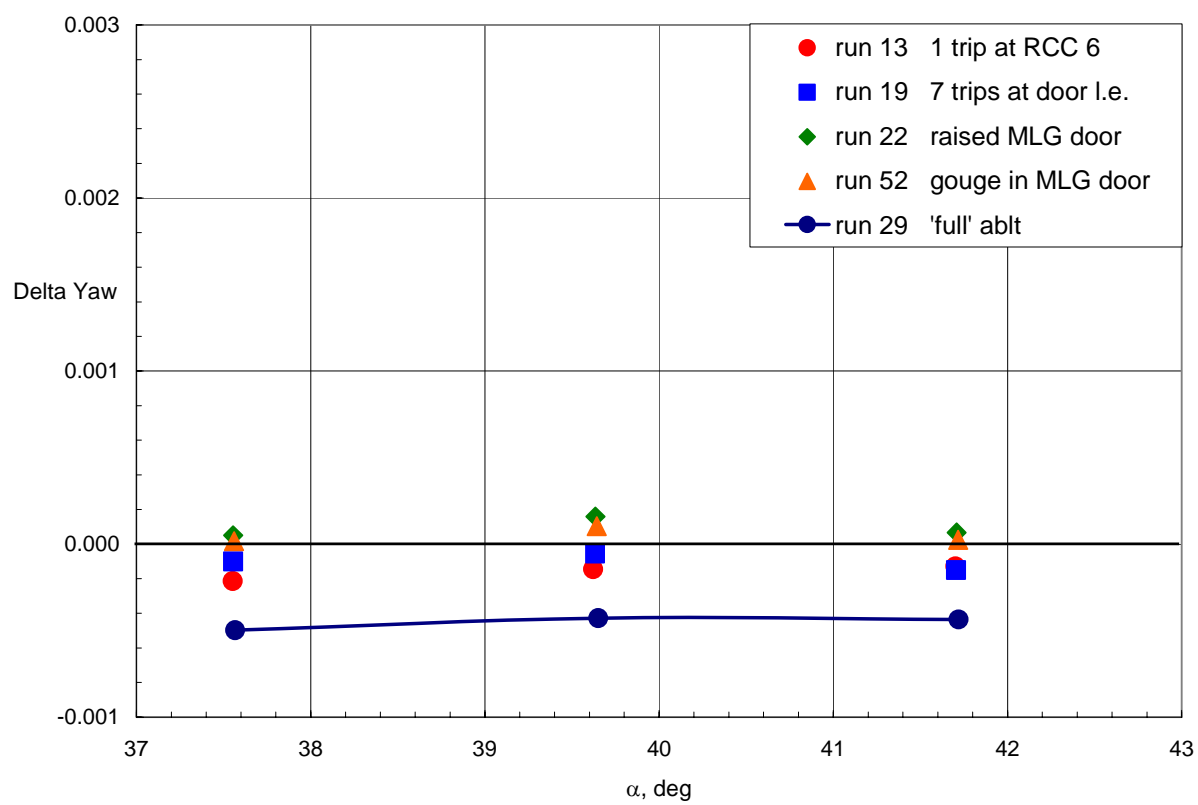

Figure 5b. Yawing-moment coefficient for various $O M L$ alterations $\left(M=6, \quad\right.$ Air, $\left.R e_{L}=2.4 \times 10^{6}\right)$

\section{RESULTS FROM 20-INCH CF 4 TUNNEL}

\section{MAIN LANDING GEAR/DOOR DEPLOYMENT}

Deployment of the main landing gear and door was tested in the $\mathrm{CF}_{4}$ tunnel, as well as the Mach 6 air tunnel. Similar results were obtained in both facilities so only the $\mathrm{CF}_{4}$ data is discussed here. Although not a primary candidate as an initiating event, this scenario was examined as a possible explanation for the large aerodynamic 
moments observed towards the end of flight. An open wheel well (no door), door alone, gear alone, and door and gear deployed were tested. Filler plates were used to create three different depths of the open wheel well in order to simulate the presence of the gear (it was thought that the presence of the gear would tend to fill in the cavity, in essence making the wheel well shallower). A sketch of these configurations is shown in figure 6 . The aerodynamic results in terms of delta rolling, yawing, and pitching moments for these configurations are shown in figure 7 . Large rolling and yawing moments were generated for the door and/or gear combinations (lines $D$ and $E$ ) consistent with flight, but pitching moments were in the opposite direction than those inferred from flight measurements. However, for the open wheel well configurations (lines A and B), as the cavity was made shallower, all three moments increased, and in the same direction as flight. This trend is consistent with "open" and "closed" type cavity flows. For the deeper cavity, some flow re-circulates within the cavity, but the main flow essentially passes over the cavity; as the depth is decreased, the flow impinges on and attaches to the cavity floor, a shock is formed as the flow reaches the aft wall, and the pressure on the cavity floor is significantly increased. This increased pressure generates the rolling, yawing, and pitching moments observed.

\section{Main Landing Gear / Door Configurations \\ - Steel Model}

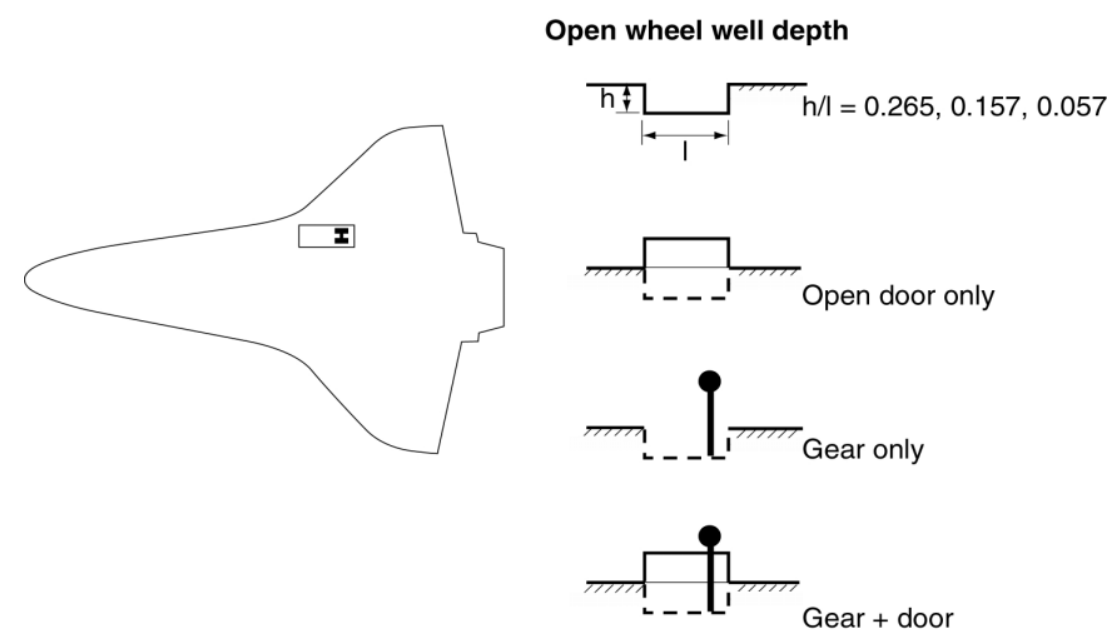

Figure 6 . Sketch of the various landing gear configurations tested 


\section{MLG Door / Gear Scenarios in 20-Inch $\mathrm{CF}_{4}$ Tunnel}

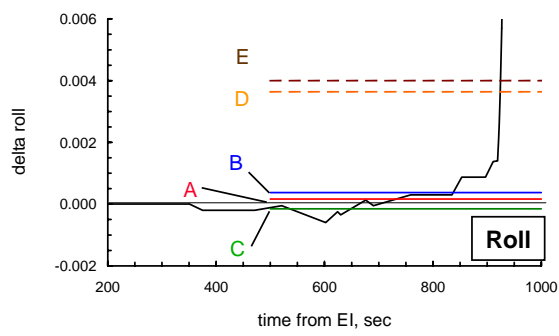

- Late in flight $(t \geq 900 \mathrm{sec})$ roll and yaw increments are of proper direction and magnitude, but pitch increment is opposite direction from flight, indicating door and gear did not deploy

- The results for an open wheel well do not rule out that the door did not come off.
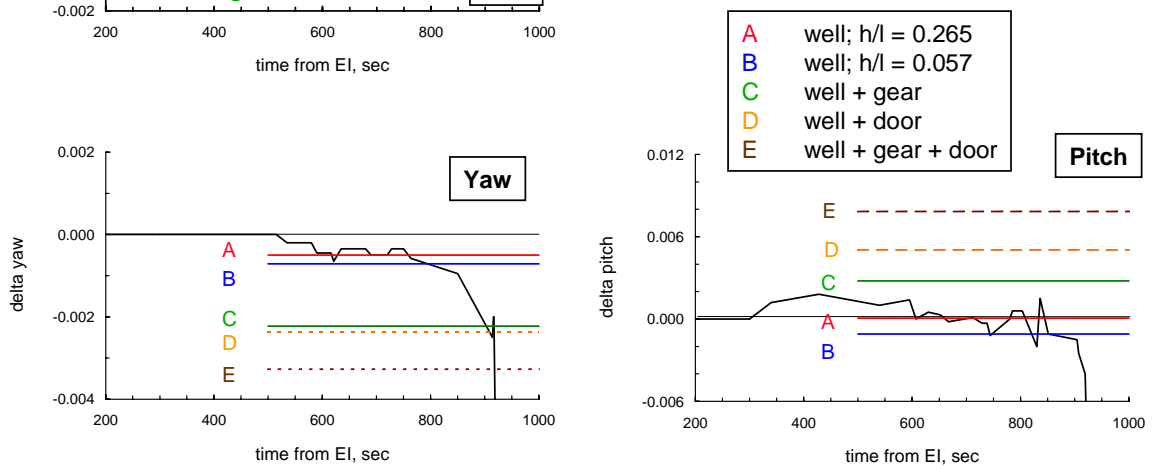

Figure 7. Aerodynamic coefficients for various landing gear configurations $\left(M=6, C F_{4}, R e_{L}=0.4 \times 10^{6}\right)$

\section{MISSING FULL RCC PANELS}

As the investigation progressed it was known that two temperature instruments on the left side of the fuselage (V34T1106A, V09T1724A) had experienced large increases in heating rates. Investigators at Langley had modified the wing leading edge with a "notch", both experimentally and computationally, and side fuselage disturbances near these gages were produced by both techniques. Given this knowledge, an extensive survey of wing leading edge damage in terms of missing RCC panels was undertaken. Five ceramic models were fabricated with one or more missing RCC panels. The missing panel area was filled and a baseline data set was generated.

The aerodynamic results for single (individual) missing panels as a function of panel location are shown in figures $8 \mathrm{a}$ through $8 \mathrm{c}$. The results show a nearly constant negative value of delta roll for a given missing panel location (figure 8a). This left-wing-down roll is believed to be due to loss of lift on the left wing due to the loss of area. Delta yawing moment (figure 8b) exhibited a relatively strong dependence on missing panel location, with a more nose-left yawing moment generated for the more outboard locations. The solid forward facing rear wall and side walls of the notch generate a shock system causing a local high-pressure area, and combined with the larger moment arm for more outboard locations, leads to the observed trend. Delta pitching moment (figure 8c) showed a dependence on missing panel location also, as nose-down pitch increased for more outboard panel locations. Superposition of single missing RCC panels was somewhat successful in predicting two-panel out increments, but less so for three or more panels missing.

Representative data for a series of tests with multiple missing RCC panels are shown in figures 9a through 9c. Data for missing panels 5, 6, 5-6, 5-7, and 6 and 9 are shown. The values of delta roll, yaw, and pitch are plotted as a constant against time from entry interface, and the flight delta aerodynamic data are also shown. Two observations are made: the small magnitude of the early flight values indicate that the damaged area in flight was not far outboard, or was smaller than an entire missing RCC panel; and the delta roll, delta yaw, and delta pitch increments all become progressively more negative (left wing down, nose left, nose down) as the number of missing panels is increased. In flight, however, the roll trend reversed, indicating that something occurred other than, or in addition to, a continuing loss of leading edge panels.

A brief series of tests examined Reynolds number effects. Missing RCC panel 9, and missing RCC panels 6 and 9 together, were tested at two Reynolds numbers, 0.27 and 0.46 per foot. No significant Reynolds number effect was observed for this factor-of-two variation in Reynolds number. 


\section{Rolling Moment Trends, Single missing panel 20-Inch $\mathrm{CF}_{4}$ Tunnel, $\quad \alpha=40^{\circ}$}

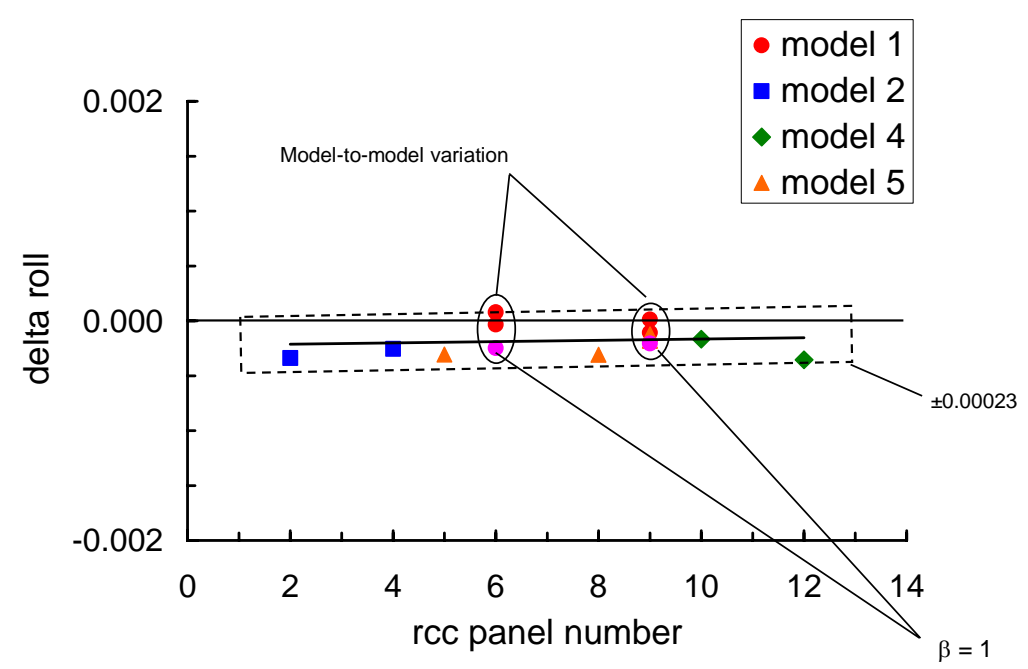

Figure 8a. Rolling-moment coefficients for individual completely missing $R C C$ panels $\left(M=6, C F_{4}, R_{L}=0.4 \times 10^{6}\right)$

\section{Yawing Moment Trends, Single missing panel} 20-Inch CF4 Tunnel, $\quad \alpha=40^{\circ}$

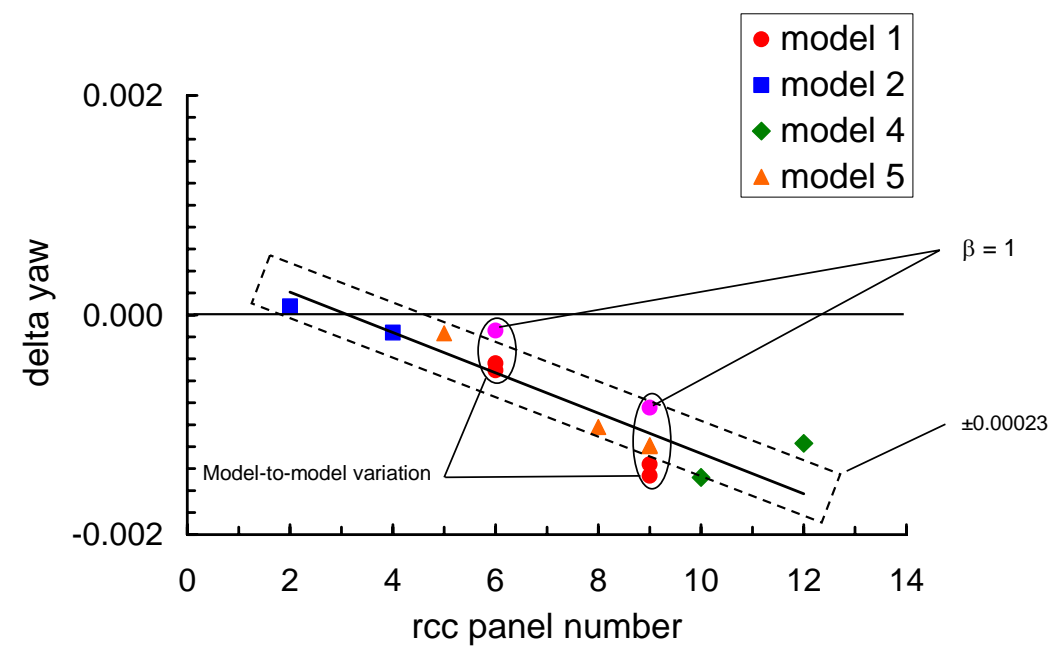

Figure 8b. Yawing-moment coefficients for individual completely missing $R C C$ panels $\left(M=6, C F_{4}, R e_{L}=0.4 \times 10^{6}\right)$ 
Pitching Moment Trends, Single missing panel 20-Inch $\mathrm{CF}_{4}$ Tunnel, $\alpha=40^{\circ}$

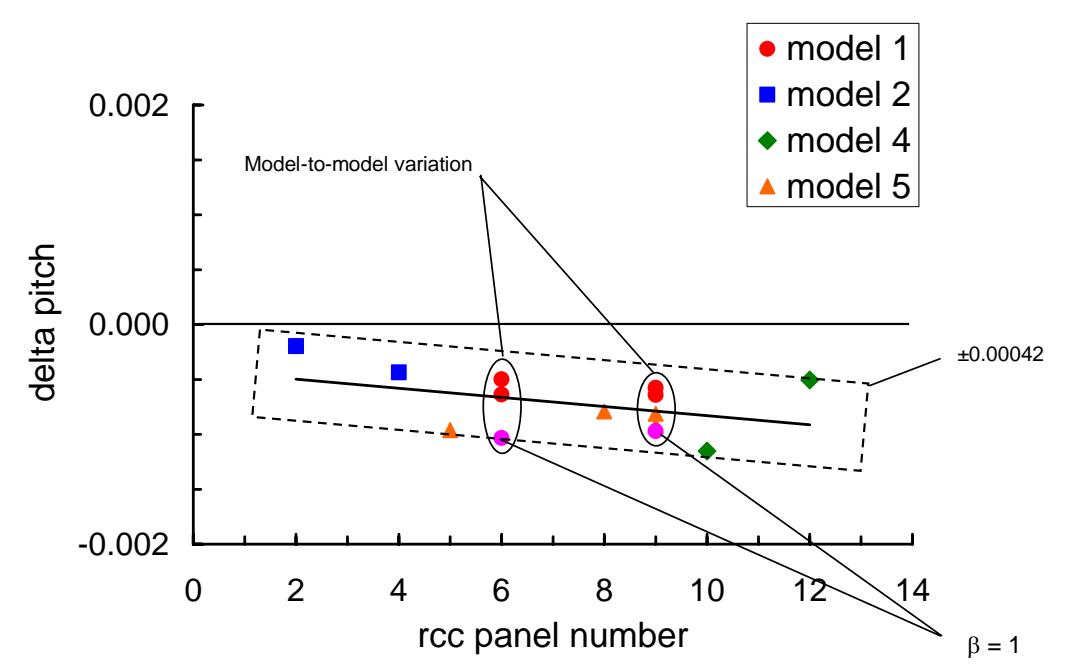

Figure 8c. Pitching-moment coefficients for individual completely missing $R C C$ panels $\left(M=6, C F_{4}, R_{L}=0.4 \times 10^{6}\right)$

\section{Rolling Moment Trends, Missing RCC Panels 5 - 9} 20-Inch $\mathrm{CF}_{4}$ Tunnel, $\alpha=40^{\circ}$

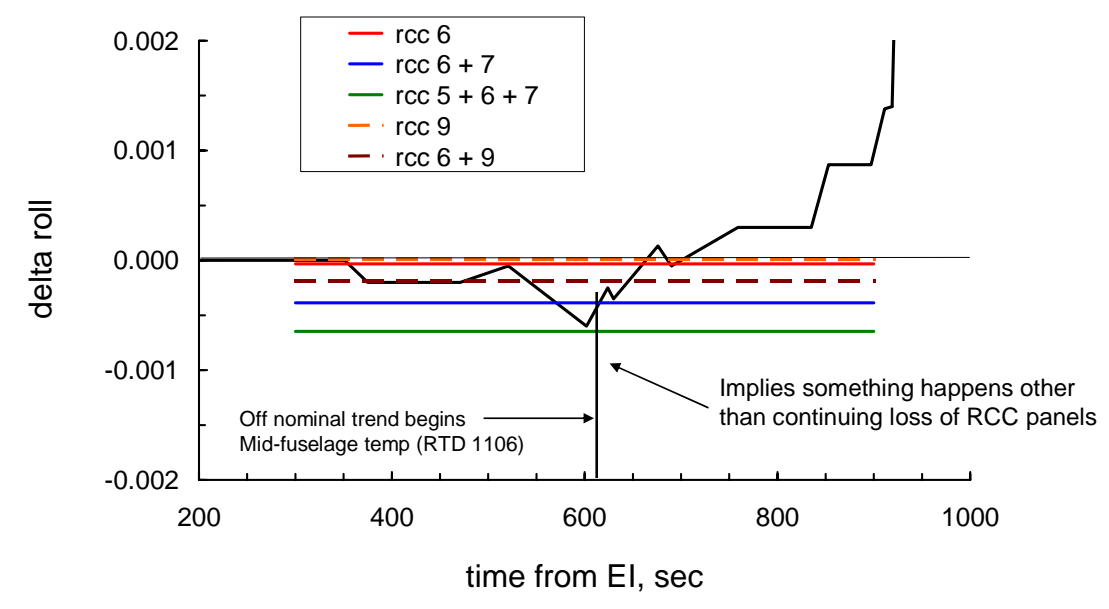

Figure 9a. Rolling-moment coefficients for one or more completely missing $R C C$ panels $\left(M=6, C F_{4}, R_{L}=0.4 \times 10^{6}\right)$ 


\section{Yawing Moment Trends, Missing RCC Panels 5 - 9 20-Inch $\mathrm{CF}_{4}$ Tunnel, $\alpha=40^{\circ}$}

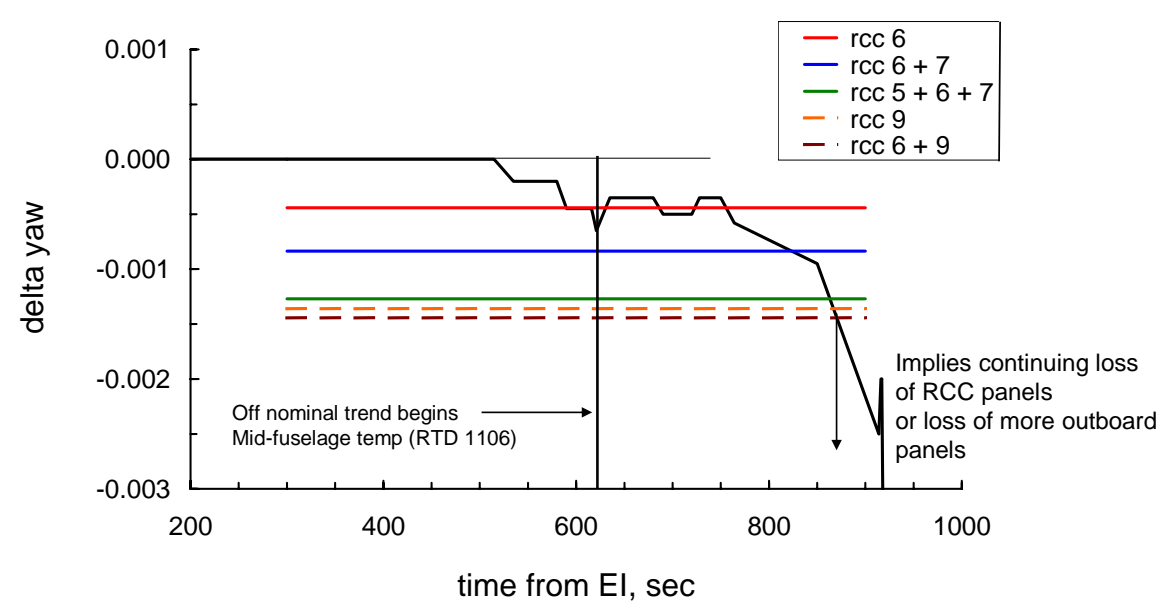

Figure 9b. Yawing-moment coefficients for one or more completely missing RCC panels $\left(M=6, C F_{4}, R_{L}=0.4 \times 10^{6}\right)$

Pitching Moment Trends, Missing RCC Panels 5 - 9 20-Inch $\mathrm{CF}_{4}$ Tunnel, $\alpha=40^{\circ}$

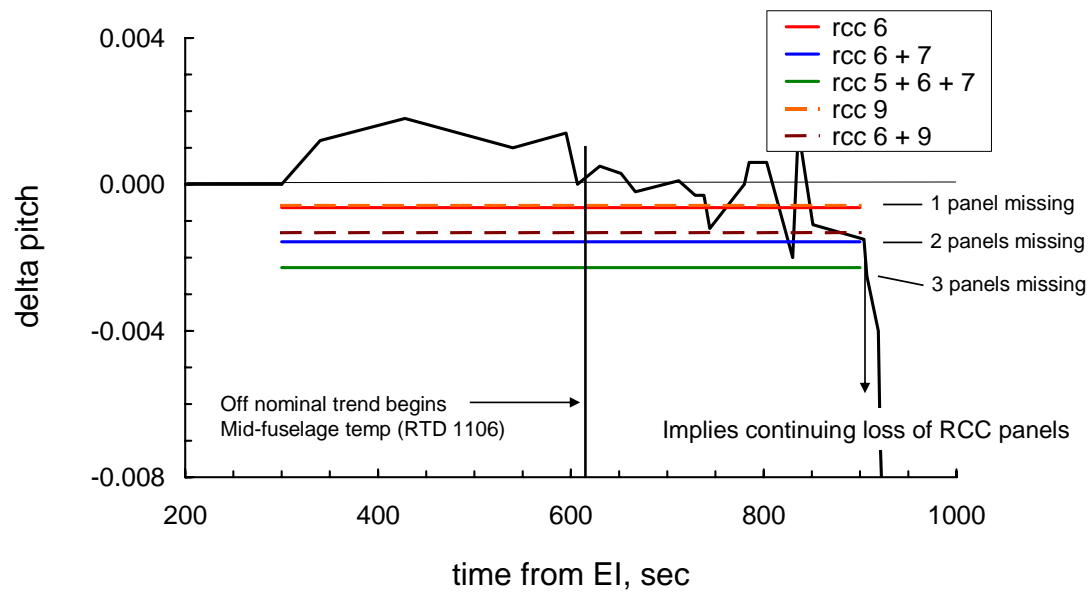

Figure 9c. Pitching-moment coefficients for one or more completely missing $R C C$ panels $\left(M=6, C F_{4}, R e_{L}=0.4 \times 10^{6}\right)$ 


\section{MISSING PARTIAL RCC PANELS}

As more of the debris was recovered and analyzed, a scenario emerged that a partially damaged RCC panel or panels may more appropriately model the actual damage, as opposed to a full panel missing. Thus a series of tests was undertaken to look at the effect of missing lower RCC panels. The wing leading edge was modified by removing the lower portion of the panel from the wing apex to the start of the lower carrier panel. The aerodynamic results for individually removed lower panels 4 through 9 are shown in figures 10a through 10c. For comparison, the full panel out data presented in the previous section are shown by the dashed line. Overall, the magnitudes of the rolling, yawing, and pitching moment increments for missing partial panels were smaller than those for a full missing panel. The rolling moment increment was slightly more positive (right wing down) for a more outboard missing panel location. This trend is believed due to the locally increased pressure acting on the underside of the RCC panel cutout, and thus as the moment arm increases with increasing outboard location, the roll becomes more positive. The yawing moment was nearly constant for any particular missing panel location, which was different than for the full panel out data where a strong dependence on panel location was seen. The pitching moment was again more nose-down for more outboard panel locations.

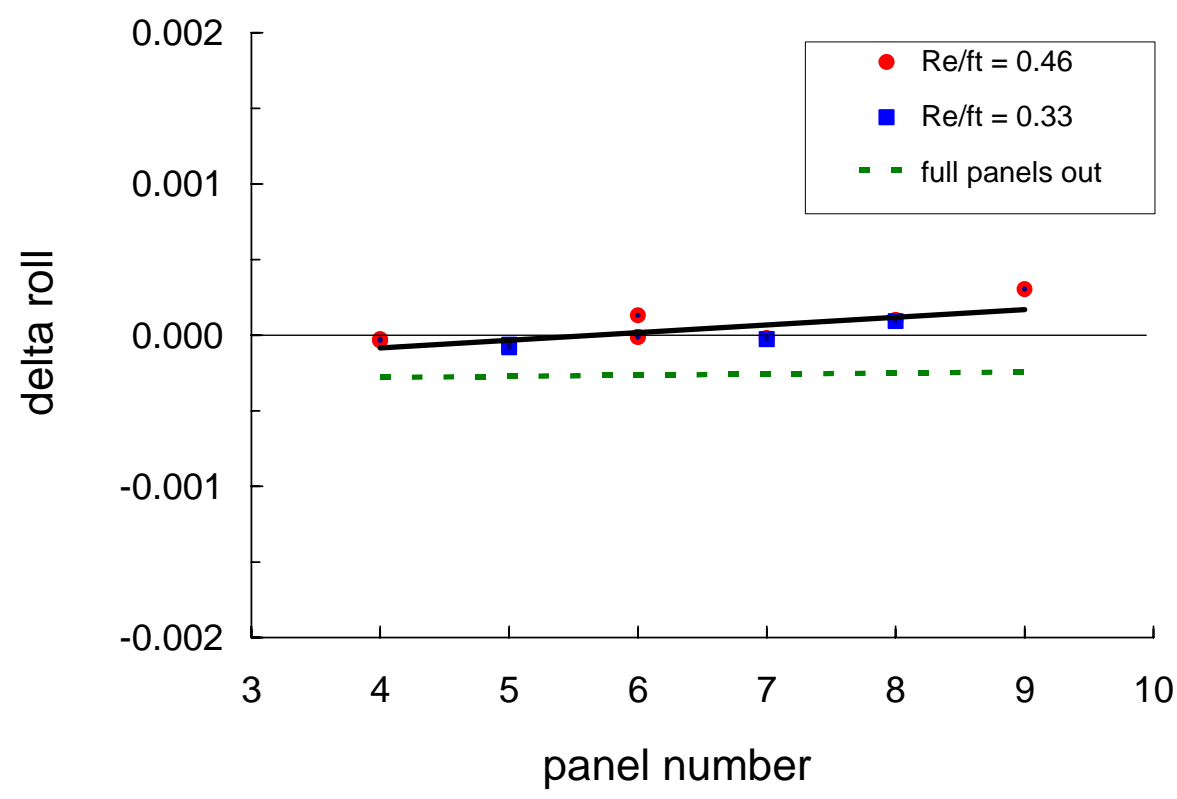

Figure 10a. Rolling-moment coefficients for individual partially missing RCC panels $\left(M=6, \quad C_{4}, \quad \operatorname{Re}_{L}=0.4 \times 10^{6}\right)$ 


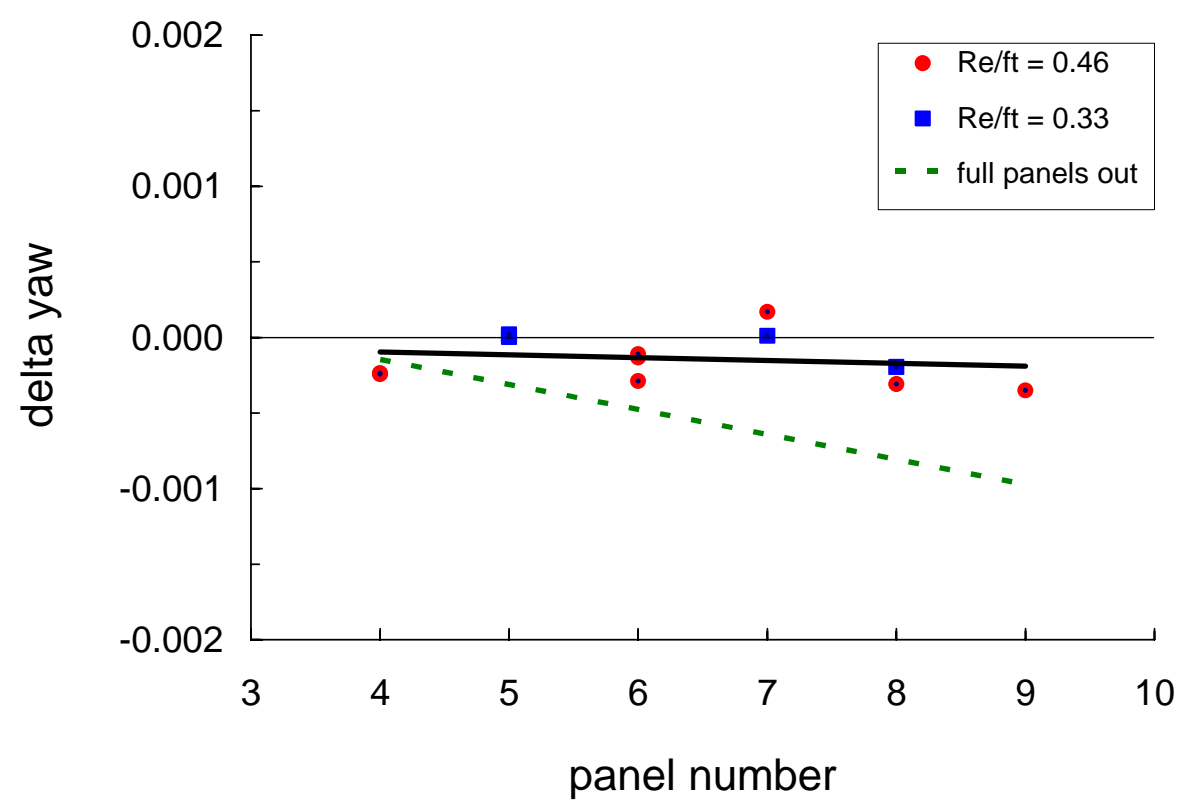

Figure 10b. Yawing-moment coefficients for individual partially missing $R C C$ panels $\left(M=6, \quad C F_{4}, \quad R e L=0.4 \times 10^{6}\right)$

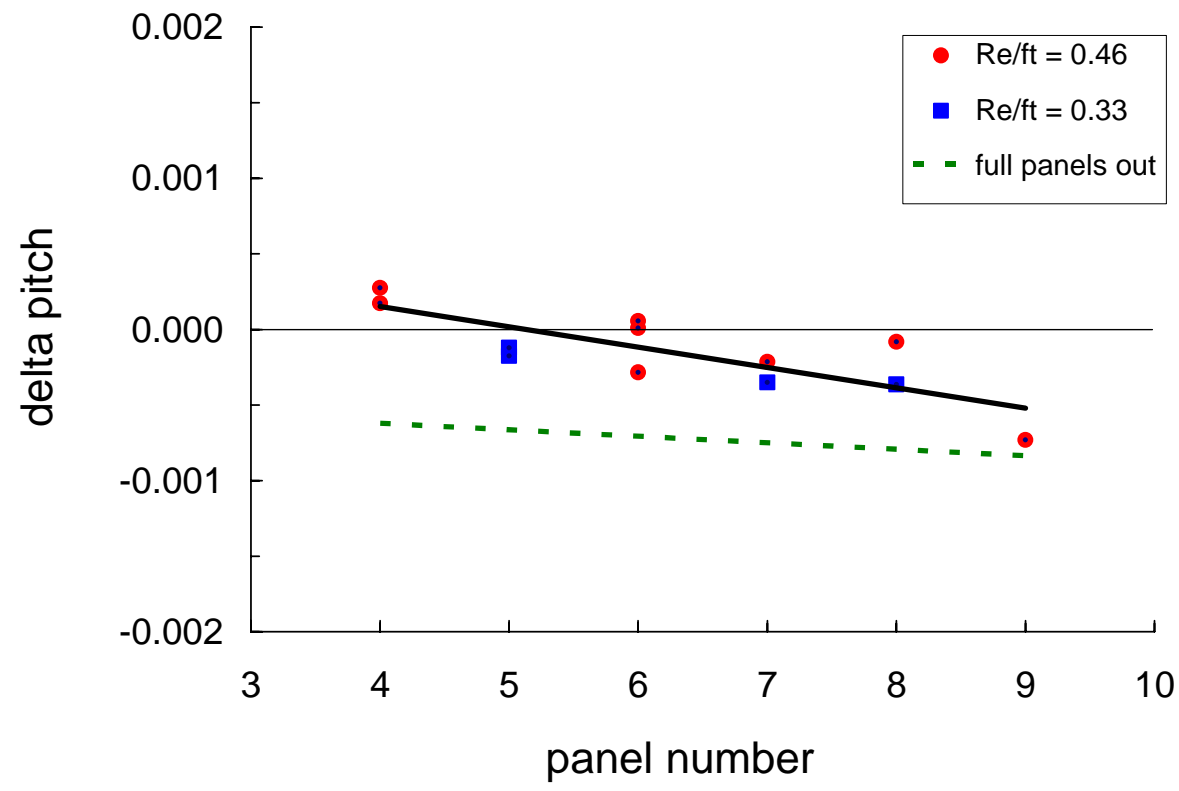

Figure 10c. Pitching-moment coefficients for individual partially missing $R C C$ panels $\left(M=6, \quad C F_{4}, \quad R e L=0.4 \times 10^{6}\right)$ 


\section{FLOW TO THE LEESIDE, HOLES AND SLOTS IN THE WING}

A recurring question during the investigation was what wing leading edge or windward surface damage scenario would provide aerodynamic characteristics observed in flight and simultaneously generate leeside disturbances (side fuselage heating) also observed in flight. This had been shown to be possible for a full missing panel. Phosphor thermography images taken for the series of missing lower RCC panels (figure 11) show that for panel 4, and to a lesser extent panel 5, a disturbance is generated that moves to the leeside of the model. This disturbance is not observed for missing partial panels 6 or 9 . The relative location of the partially missing panel to the local attachment line largely determines if the disturbance is swept to the leeside or not.

Another mechanism examined for flow reaching the leeside was through holes or slots in the upper surface. For one series of tests, small holes (0.030-inch diameter model scale, 4 inch diameter full scale) were drilled through the wing, from windward surface to the leeside, at the carrier panel locations behind RCC panels 6, 9, and 12 (separate runs). No effect of these holes through the wing was seen in either the aerodynamic increments or the side fuselage images. For another series of tests, a 0.030-inch hole was drilled from the windward surface (center, aft end of the partially missing panel 8 ) to the leeside side through upper carrier panel 8 . Afterwards this hole was widened to a 0.030 -inch slot, in effect removing most of the upper carrier panel. Phosphor thermography images of the fuselage side are shown in figure 12. A slight effect on heating to the OMS pod can be seen for the single hole. The slot creates a larger disturbance in the leeside flow field, resulting in increased heating on the side of the fuselage and the OMS pod, similar to that observed for a full missing panel, though the heating rate is lower. The aerodynamic increments in rolling and pitching moments associated with the hole and slot are very small, but there is a measurable increase in the nose-left yawing moment increment when the hole is widened to a slot.

\section{Side impingement as function of panel location - lower half panel removed}

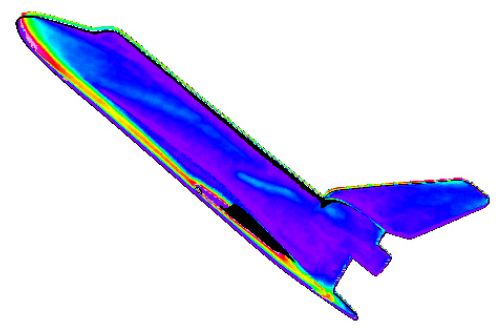

missing lower rcc 4

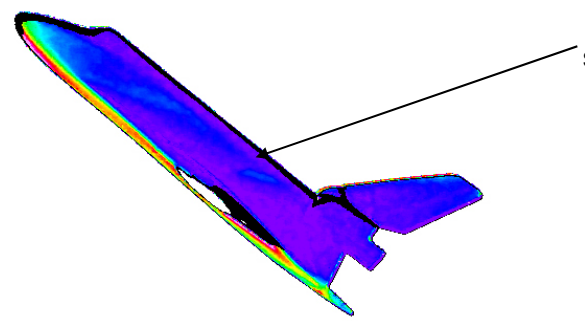

missing lower rec 5
Region near RCC panels $4-6$ is dividing line for flow moving to leeside.

Faint disturbance een for panel 5 similar break in side "vortex" but fainter than for panel 4

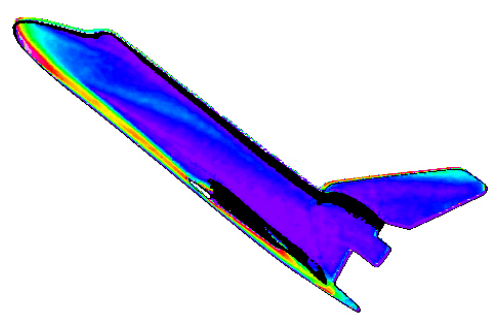

missing lower rcc 6

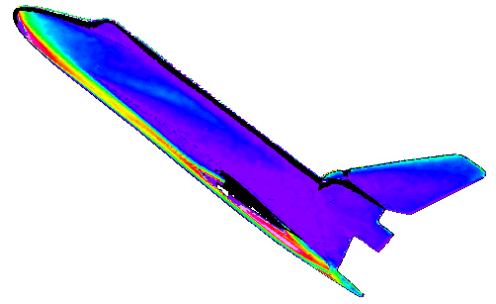

missing lower rcc 9

Figure 11. Thermographic phosphor images for partially missing lower $\mathrm{RCC}$ panels $\left(\mathrm{M}=6, \mathrm{CF}_{4}, \mathrm{Re}_{\mathrm{L}}=0.4 \times 10^{6}\right)$ 


\section{Effect of hole or slot through upper carrier panel - missing lower RCC panel 8}

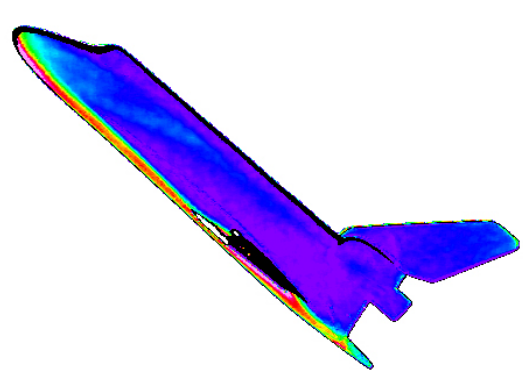

without hole through carrier panel

\author{
Flow through slot in \\ upper carrier panel \\ (panel 8) affects both \\ leeside side fuselage \\ and OMS pod. \\ Small effect on OMS \\ pod only with hole \\ Yawing moment \\ increment increases \\ with slot present
}

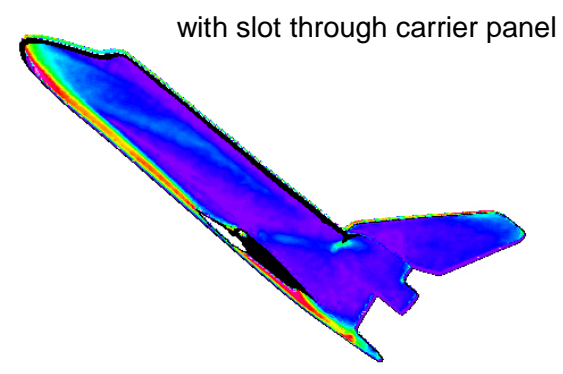

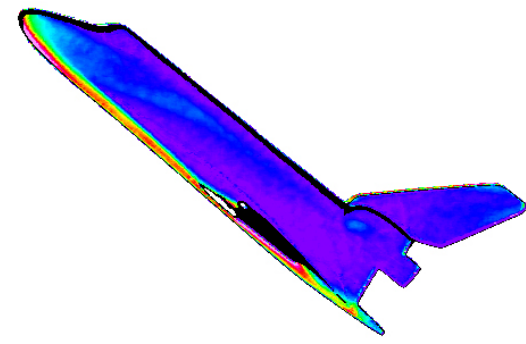

with hole through carrier panel
Hole diameter

4.0 in full scale

Hole area

12.6 in^2 full scale

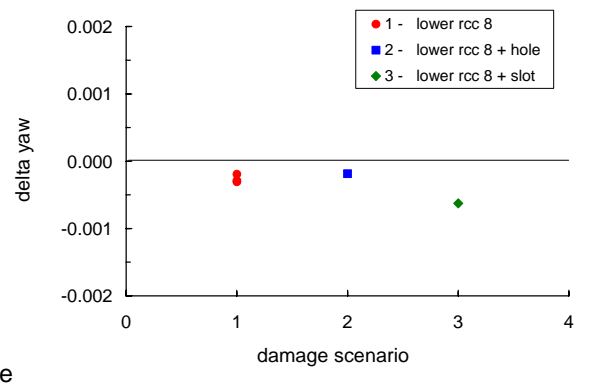

Figure 12. Thermographic phosphor images for holes and slots through left wing $\left(M=6, C F_{4}, \quad R e_{L}=0.4 \times 10^{6}\right)$

\section{EFFECT OF THE VERTICAL TAIL}

Another aspect that was investigated was whether flow to the leeside was impinging on or in some way affecting the flow on the vertical tail. A piece of the vertical tail had been found that showed damage to the left side, but not the right. In addition, the tail was seen as a possible contributor to the large roll and yaw increments seen late in flight, and especially for the change in rolling moment behavior. A model was tested with the tail on and off, with and without panel 9 missing. As seen in table 3 for missing RCC panel 9, the increments with and without the vertical tail are very close in value, leading to the conclusion that the tail was not affected nor a contributor to the moments in question.

Table 3: Effect of vertical tail

\begin{tabular}{|c|c|c|c|c|c|c|c|c|}
\hline Run & Tail & Alpha & $\mathrm{Re} / \mathrm{ft}$ & $\Delta \mathrm{Crm}$ & $\Delta$ Cym & $\Delta \mathrm{Cm}$ & $\Delta C Y$ & Model \\
\hline 30 & on & 40.2 & 0.45 & -0.00006 & -0.00115 & -0.00105 & 0.00013 & A \\
\hline 44 & on & 40.5 & 0.46 & 0.00007 & -0.00131 & -0.00128 & -0.00037 & 5 \\
\hline 45 & on & 40.5 & 0.45 & 0.00008 & -0.00132 & -0.00128 & 0.00022 & 5 \\
\hline 63 & off & 40.5 & 0.46 & -0.00007 & -0.00122 & -0.00125 & -0.00006 & 5 \\
\hline 64 & off & 40.5 & 0.44 & -0.00013 & -0.00122 & -0.00117 & 0.00006 & 5 \\
\hline Avg & on & 40.4 & 0.45 & 0.00003 & -0.00126 & -0.00120 & -0.00001 & \\
\hline Avg & off & 40.5 & 0.45 & -0.00010 & -0.00122 & -0.00121 & 0.00000 & \\
\hline Delta & & -0.1 & 0.00 & 0.00013 & -0.00004 & 0.00001 & -0.00001 & \\
\hline
\end{tabular}




\section{WINDWARD SURFACE DEPRESSION}

A final series of aerodynamic tests were performed to determine if a damage scenario related to deformation of the left wing would cause the change in direction of the rolling moment seen to occur 615 seconds after entry interface. Influenced by the results from the open wheel well, a shallow depression was created in the left wing windward surface to simulate what might occur as the wing internal structure was degraded and the lower skin was pressed inward by the greater external surface pressure. A single groove was milled into the lower surface of the model, starting just behind RCC panel 8. The length of this groove was varied in three increments with the longest groove extending slightly past the aft end of the wheel well. This groove was then widened to simulate progressive damage. Measured aerodynamic moments show (figure 13a through 13c) that a minimum length of the groove is needed to provide a measurable increase in rolling moment, similar to the critical depth of the open wheel well. The required aspect ratio $(\mathrm{L} / \mathrm{h})$ of the groove is greater than for the open wheel well; this effect may be related to the angle of the local streamlines, in that they will cross the groove as opposed to running parallel to it, thus in effect shortening the groove and reducing the aspect ratio. In any case, the depression does indeed cause a positive (right wing down) rolling moment as observed in flight, and the magnitude of the rolling moment increases as the width of the depression is increased. Furthermore, the yawing moment and pitching moment generated by the depression are similar in magnitude and in the same direction as observed for flight.

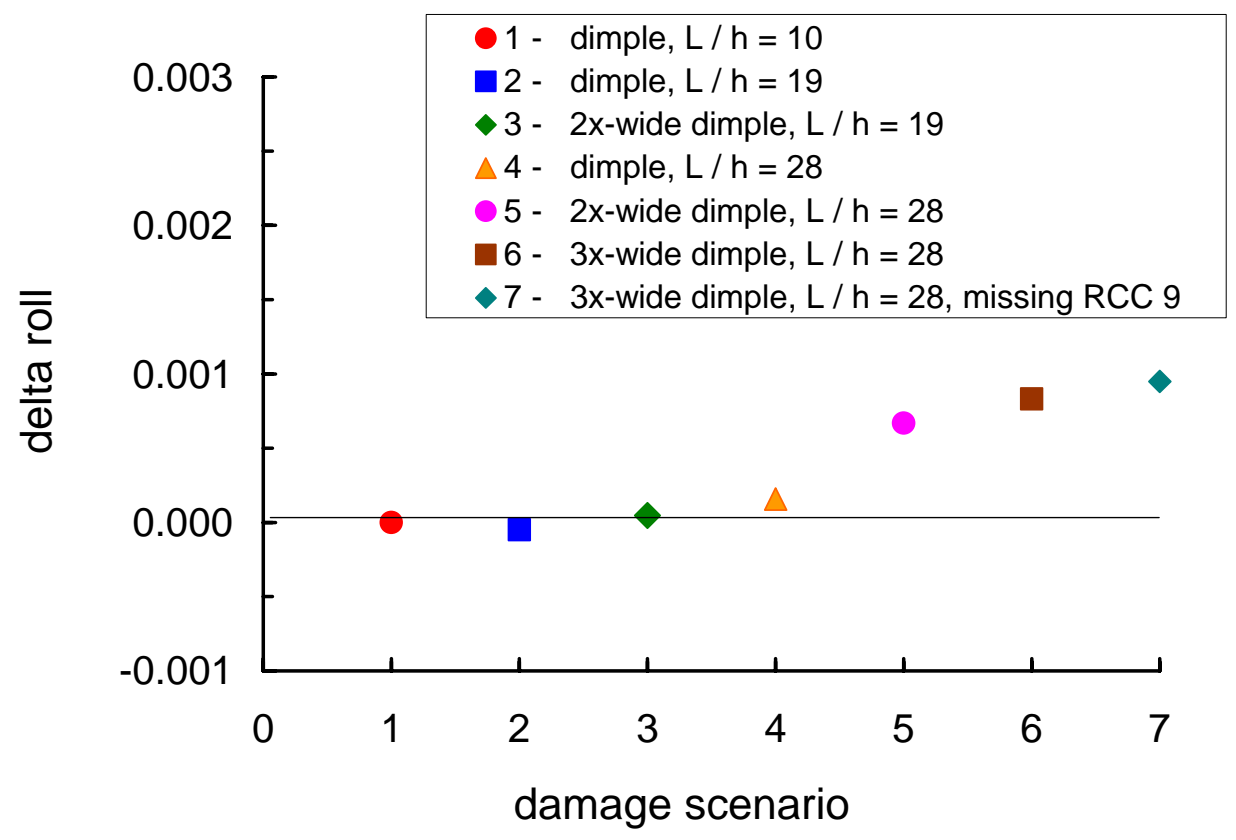

Figure 13a. Rolling-moment coefficients for various windward surface damage scenarios $\left(M=6, C F_{4}, R_{L}=0.4 \times 10^{6}\right)$ 


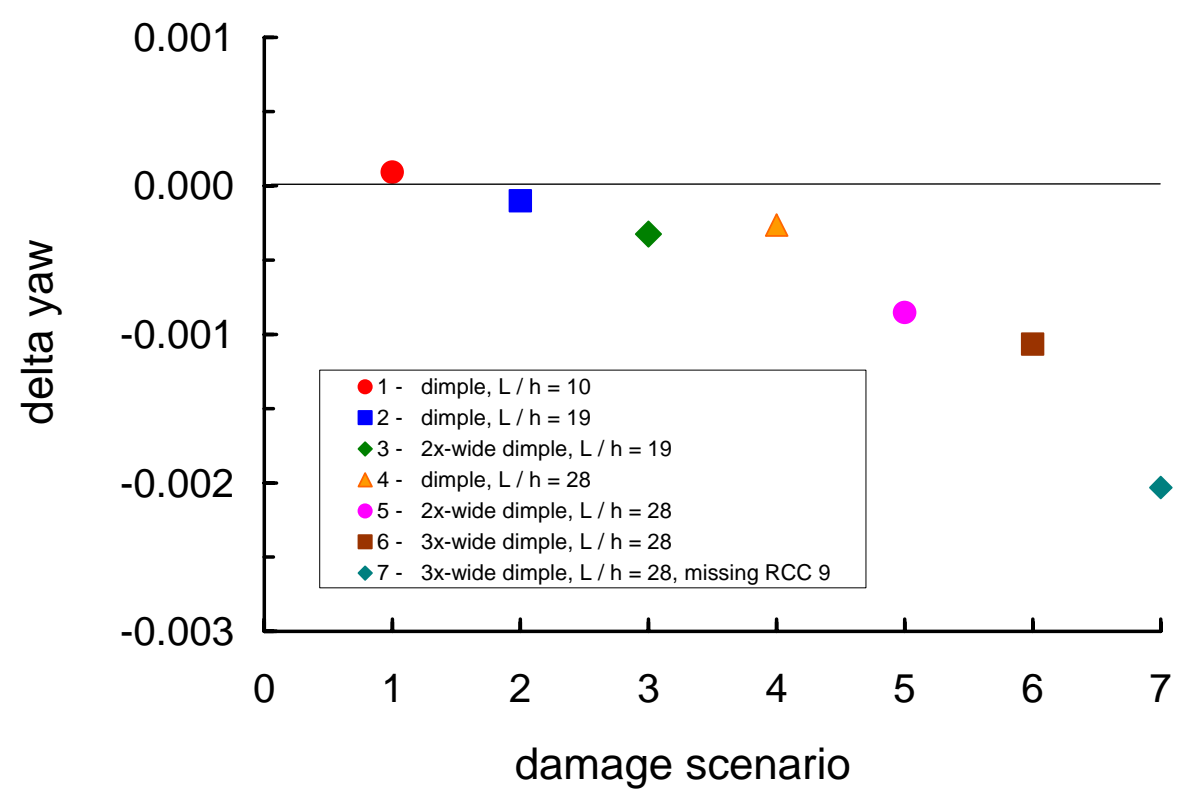

Figure 13b. Yawing-moment coefficients for various windward surface damage scenarios $\left(\mathrm{M}=6, \mathrm{CF}_{4}, \mathrm{Re}_{\mathrm{L}}=0.4 \times 10^{6}\right)$

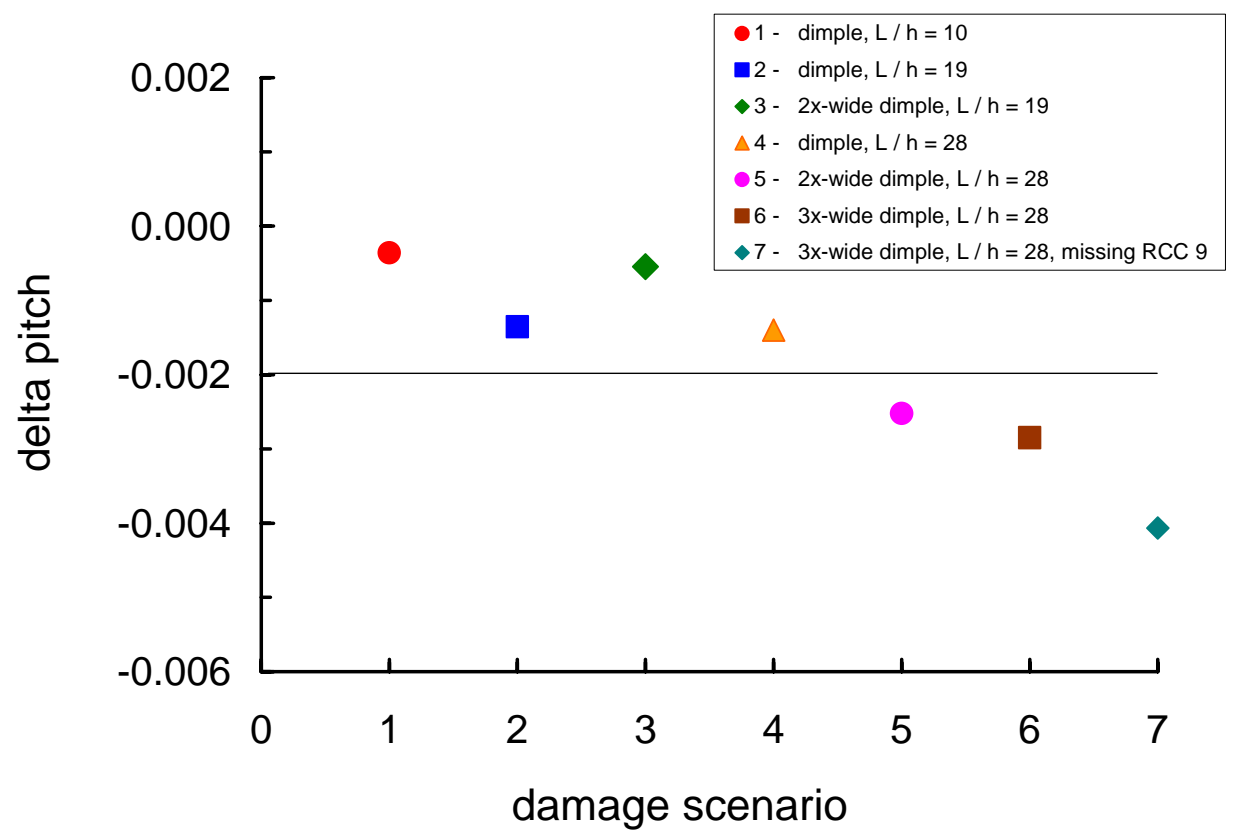

Figure 13c. Pitching-moment coefficients for various windward surface damage scenarios $\left(M=6, C F_{4}, R_{L}=0.4 \times 10^{6}\right)$

\section{PROGRESSIVE DAMAGE SCENARIO}

As a final summation to the aerodynamic work, a progressive build-up of individual damage scenarios was developed and compared to the flight moment increments. The results are shown in figures $14 \mathrm{a}$ through 14c. The annotated times from entry interface are subjective, as are the damage scenarios themselves. Nonetheless, a plausible scenario can be developed, which has the same trends as the flight data, although an exact correlation of flight magnitudes and time is not achieved. The initial damage is loss of the lower portion of RCC panel 8 . The 
magnitudes of the moment increments are small, as they were for the first 500 seconds or so of flight. This initial damage is followed by the addition of the slot through the upper portion of carrier panel 8 , and then the complete removal of panel 9 at 615 seconds from entry interface $(\mathrm{EI})$. It was at this time (615 seconds) that significant heating to the side fuselage was seen, and both the slot in carrier panel 8 and the complete removal of panel 9 allow flow to impinge on the leeside of the vehicle. The reversal in direction of the rolling moment is attributed to the windward surface depression, with the magnitude increasing as the size of the depression is increased (as more of the internal wing structure is degraded). The yawing and pitching moments continue their increasing negative trend as the depression is enlarged.

\section{Progressive damage scenario - roll}

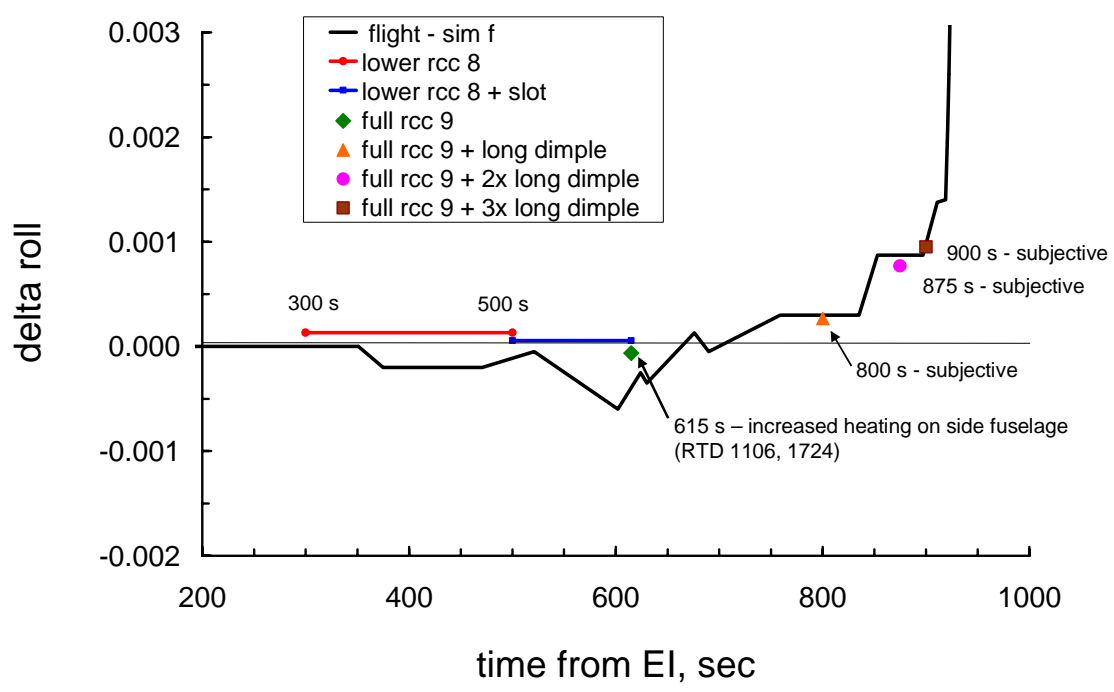

Figure 14a. Rolling-moment coefficients for various damage scenarios $\left(M=6, \quad C F_{4}, \quad R e_{L}=0.4 \times 10^{6}\right)$ 


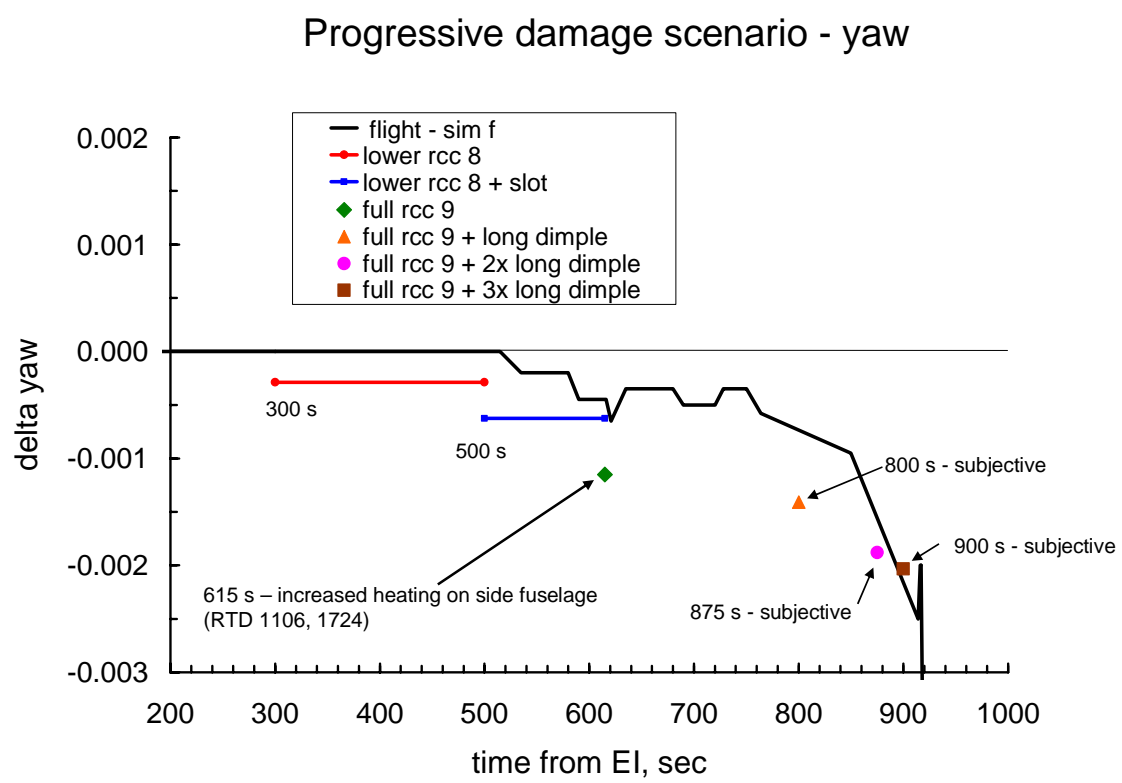

Figure 14b. Yawing-moment coefficients for various damage scenarios $\left(M=6, \quad C F_{4}, \quad R e_{L}=0.4 \times 10^{6}\right)$

Progressive damage scenario - pitch

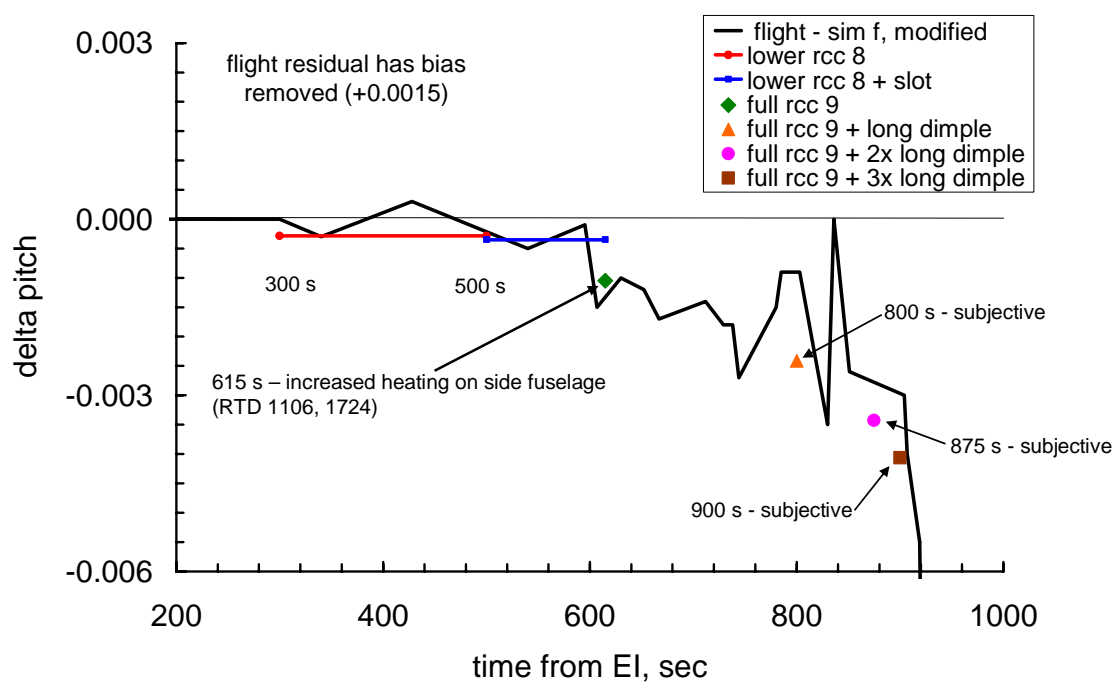

Figure 14c. Pitching-moment coefficients for various damage scenarios $\left(M=6, \quad C_{4}, \quad R e L=0.4 \times 10^{6}\right)$ 


\section{SUMMARY AND CONCLUSIONS}

Aerodynamic tests in support of the Columbia accident investigation were conducted in two hypersonic wind tunnels at the NASA Langley Research Center, the 20-Inch Mach 6 Air Tunnel and the 20-Inch Mach $6 \mathrm{CF}_{4}$ Tunnel. The damage scenarios evaluated included asymmetric boundary layer transition, gouges in the windward surface acreage thermal protection system tiles, wing leading edge damage (partially and fully missing reinforced carboncarbon (RCC) panels), holes through the wing from the windward surface to the leeside, deformation of the wing windward surface, and main landing gear door and/or gear deployment. The aerodynamic data were compared to the magnitudes and directions observed in flight, and the heating images were evaluated in terms of the location of the generated disturbances and how these disturbance might relate to the response of discrete gages on the Columbia Orbiter vehicle during entry.

The measured aerodynamic increments in general were small in magnitude, as were the flight-derived values during most of the entry. Asymmetric boundary layer transition (ABLT) results were consistent in sign with the flightderived Shuttle ABLT model, but not with the observed flight trends for STS-107, suggesting that ABLT was not an issue during this flight. The partially missing leading edge panel scenario best matched both the aerodynamic and heating trends observed early in flight (small aerodynamic moments with flow impingement increasing the heating on the lee side fuselage), and the recovered debris on the ground (a portion of all RCC panels was recovered). A progressive damage scenario was presented that qualitatively matches the aerodynamic flight observations (rolling, yawing, and pitching moments) for the entire trajectory: loss of the lower portion of RCC 8, loss of the upper carrier panel behind RCC 8 (slot through the wing), a windward surface depression, and growth of the windward surface depression.

\section{REFERENCES}

1. Columbia Accident Investigation Board Report, Volume I, August 2003.

2. Madsen, C. M., Labbe, S. G., and Carvajal, O.: STS-107 Aerodynamics - Off Nominal Aerodynamic Extraction, JANNAF $27^{\text {th }}$ Airbreathing Propulsion Subcommittee, Colorado Springs, 2003.

3. NSTS-37398, Aero/Aerothermal/Thermal/Structures Team Final Report in Support of the Columbia Accident Investigation, August 6, 2003

4. Miller, C. G.: Langley Hypersonic Aerodynamic/Aerothermodynmaic Testing Capabilities - Present and Future, AIAA Paper 90-1376.

5. Brauckmann, G.J., Paulson, J. W. Jr., and Weilmuenster, K. J.: Experimental and Computational Analysis of Shuttle Orbiter Hypersonic Trim Anomaly, Journal of Spacecraft and Rockets, Vol. 32, No. 5, SeptemberOctober 1995.

6. NSTS-37398, Aero/Aerothermal/Thermal/Structures Team Final Report in Support of the Columbia Accident Investigation, August 6, 2003

7. Buck, G. M.: Rapid Model Fabrication and testing for Aerospace vehicles, AIAA paper 2000-0826.

8. Buck, G. M., and Vasquez, P.:An Investment Ceramic Slip casting technique for Net-Form, Precison, Detailed casting of Ceramic Models, U.S. patent 5,266,252.

9. Daryabeigi, K., Berry, S. A., Horvath, T. J., and Nowak, R. J.: Finite Volume Numerical Methods for Aeroheating Rate Calculations from Infrared Thermographic Data, AIAA paper 2003-3634.

10. Merski, N. R.: Reduction and Analyisis of Phosphor Thermographgy data with the IHEAT Software Package, AIAA paper 98-0712.

11. Merski, N. R.: Global Aeroheating Wind-Tunnel Measurements Using Improved Two-Color Phopshor Thermography Method, Journal of Spacecraft and Rockets, Vol 36, No. 2, 1998.

12. An, M. Y., Wang, K. C., Campbell, C. H., and Pelley, R. L.: Space Shuttle Orbiter Aerodynamics Induced by Asymmetric Boundary-Layer Transition, AIAA 96-0808, January 15-18, 1996 